\title{
Large-scale atmospheric circulation biases and changes in global climate model simulations and their importance for climate change in Central Europe
}

\author{
A. P. van Ulden and G. J. van Oldenborgh \\ KNMI, P.O. Box 201, 3730 AE De Bilt, The Netherlands \\ Received: 1 June 2005 - Published in Atmos. Chem. Phys. Discuss.: 25 August 2005 \\ Revised: 23 December 2005 - Accepted: 27 January 2006 - Published: 20 March 2006
}

\begin{abstract}
The quality of global sea level pressure patterns has been assessed for simulations by 23 coupled climate models. Most models showed high pattern correlations. With respect to the explained spatial variance, many models showed serious large-scale deficiencies, especially at midlatitudes. Five models performed well at all latitudes and for each month of the year. Three models had a reasonable skill.

We selected the five models with the best pressure patterns for a more detailed assessment of their simulations of the climate in Central Europe. We analysed observations and simulations of monthly mean geostrophic flow indices and of monthly mean temperature and precipitation. We used three geostrophic flow indices: the west component and south component of the geostrophic wind at the surface and the geostrophic vorticity. We found that circulation biases were important, and affected precipitation in particular. Apart from these circulation biases, the models showed other biases in temperature and precipitation, which were for some models larger than the circulation induced biases.

For the 21 st century the five models simulated quite different changes in circulation, precipitation and temperature. Precipitation changes appear to be primarily caused by circulation changes. Since the models show widely different circulation changes, especially in late summer, precipitation changes vary widely between the models as well. Some models simulate severe drying in late summer, while one model simulates significant precipitation increases in late summer. With respect to the mean temperature the circulation changes were important, but not dominant. However, changes in the distribution of monthly mean temperatures, do show large indirect influences of circulation changes. Especially in late summer, two models simulate very strong warming of warm
\end{abstract}

Correspondence to: A. P. van Ulden

(aad.van.ulden@knmi.nl) months, which can be attributed to severe summer drying in the simulations by these models. The models differ also significantly in the simulated warming of cold winter months. Finally, the models simulate rather different changes in North Atlantic sea surface temperature, which is likely to impact on changes in temperature and precipitation. These results imply that several important aspects of climate change in Central Europe are highly uncertain. Other aspects of the simulated climate change appear to be more robust. All models simulate significant warming all year round and an increase in precipitation in the winter half-year.

\section{Introduction}

Global coupled climate models are indispensable tools in climate analysis. Such models are credible if they are able to produce realistic simulations of large scale patterns of the atmospheric circulation and of other climate variables. An assessment of the performance of global coupled models can be found in the Third Assessment Report of the IPCC (2001), and in Bader et al. (2004). Recently many new coupled model simulations have been made, both for the 20th century climate and for various future emission scenarios. Model output has been made accessible for analysis by external groups, in preparation for the Fourth Assessment Report of IPCC (see acknowledgements and Table 1). This has created a unique opportunity to compare simulations by many different models with observations, and to compare climate change projections by these models.

This paper starts with an assessment of the quality of global fields of the mean sea level pressure, as simulated by all 23 models for the 20th century. This assessment is presented in Sect. 2. Based on this test, we selected a set of

Published by Copernicus GmbH on behalf of the European Geosciences Union. 
Table 1. Models included in this study.

\begin{tabular}{|c|c|c|c|c|c|}
\hline Model name & Short name & $\begin{array}{l}\text { Originating } \\
\text { group(s) }\end{array}$ & Country & $\begin{array}{l}\text { Atmospheric } \\
\text { Resolution }\end{array}$ & Reference \\
\hline BCCR-BCM2.0 & BCCR2 & Bjerknes Centre & Norway & T63,L31 & Furevik et al. (2003) \\
\hline BCC-CM1 & $\mathrm{BCC}$ & Beijing Climate Centre & China & T63,L16 & Ding et al. (2004) \\
\hline CCSM3.1 & CCSM & NCAR & USA & T85,L26 & Collins et al. $(2005)^{1}$ \\
\hline CGCM3.1(T47) & $\mathrm{CCC} 47$ & CCCMA & Canada & T47,L31 & Kim et al. (2002) \\
\hline CGCM3.1(T63) & CCC63 & CCCMA & Canada & T63,L31 & Flato $(2005)^{2}$ \\
\hline CNRM-CM3 & CNRM3 & Météo-France/CNRM & France & T63L45 & Salas-Mélia et al. $(2005)^{3}$ \\
\hline CSIRO-Mk3.0 & CSIRO3 & CSIRO & Australia & T63,L18 & Gordon et al. (2002) \\
\hline ECHAM5/MPI-OM & ECHAM5 & MPI & Germany & T63,L31 & Jungclaus et al. $(2005)^{4}$ \\
\hline ECHO-G & ECHO & MIUB et al. & Ger/Kor. & T30,L19 & Min et al. (2005) \\
\hline FGOALS-g1.0 & FGOALS & LASG/IAP & China & $\mathrm{T} 42, \mathrm{~L} 26$ & Yu et al. (2004) \\
\hline GFDL-CM2.0 & GFDL2.0 & GFDL & USA & $2.5^{\circ} \times 2^{\circ}, \mathrm{L} 24$ & Delworth et al. (2005) \\
\hline GFDL-CM2.1 & GFDL2.1 & GFDL & USA & $2.5^{\circ} \times 2^{\circ}, \mathrm{L} 24$ & Delworth et al. (2005) \\
\hline GISS-AOM & GISSaom & NASA/GISS & USA & $4^{\circ} \times 3^{\circ}, \mathrm{L} 12$ & Lucarini and Russell (2002) \\
\hline GISS-EH & GISSeh & NASA/GISS & USA & $5^{\circ} \times 4^{\circ}, \mathrm{L} 20$ & Schmidt et al. (2006) \\
\hline GISS-ER & GISSer & NASA/GISS & USA & $5^{\circ} \times 4^{\circ}, \mathrm{L} 20$ & Schmidt et al. (2006) \\
\hline INM-CM3.0 & INM3 & INM & Russia & $5^{\circ} \times 4^{\circ}, \mathrm{L} 21$ & Volodin and Diansky (2004) \\
\hline IPSL-CM4 & IPSL4 & IPSL & France & $2.5^{\circ} \times 3.75^{\circ}, \mathrm{L} 19$ & Marti et al. (2005) \\
\hline MIROC3.2(hires) & MIROChi & CCSR, NIES, FRCGC & Japan & T106,L56 & K-1 model developers (2004) \\
\hline MIROC3.2(medres) & MIROCm & CCSR, NIES, FRCGC & Japan & T42,L20 & K-1 model developers (2004) \\
\hline MRI-CGCM2.3.2 & MRI2.3.2. & MRI & Japan & T42,L30 & Yukimoto and Noda (2002) \\
\hline PCM & PCM & NCAR & USA & T42,L18 & Washington et al. (2000) \\
\hline UKMO-HadCM3 & HadCM3 & UKMO & UK & $3.75^{\circ} \times 2.5^{\circ}, \mathrm{L} 19$ & Gordon et al. (2000) \\
\hline UKMO-HadGEM1 & HadGEM1 & UKMO & UK & $1.875^{\circ} \times 1.25^{\circ}, \mathrm{L} 38$ & Johns et al. (2004) \\
\hline
\end{tabular}

${ }^{1}$ Collins, W. D., Bitz, C. M., Blackmon, M. I., Bonan, G. B., Bretherton, C. S., Carton, J. A., Chang, P., Doney, S. C., Hack, J. J., Henderson, T. B., Kiehl, J. T., Large, W. G., McKenna, D. S., Santer, B. D., and Smith, R. D.: The Community Climate System Model: CCSM3, J. Climate, submitted, 2005.

${ }^{2}$ Flato, G. M.: The third generation coupled global climate model (CGCM3), www.cccma.bc.ca/modelscgcm2.shtml

${ }^{3}$ Salas-Mélia, D., Chauvin, F., Déqué, M., Douville, H., Gueremy, J. F., Marquet, P., Planton, S., Royer, J. F., and S., T.: Description and validation of the CNRM-CM3 global coupled model, Climate Dyn., submitted, 2005.

4 Jungclaus, J. H., Keenlyside, N., Botzet, M., Haak, H., Luo, J.-J., Latif, M., Marotzke, J., Mikolajewicz, U., and Roeckner, E.: Ocean circulation and tropical variability in the coupled model ECHAM5/MPI-OM, J. Climate, accepted, 2006.

models with realistic SLP patterns over the globe and over Europe for a more detailed analysis of the climate in Europe.

The climate in Europe depends strongly on the atmospheric circulation. Westerlies carry moist maritime air from the Atlantic Ocean to the continent, while easterlies bring dry and cold weather in winter and dry and warm weather in summer. Biases in the mean circulation are indications for important model deficiencies, such as a poor representation of the frequency of atmospheric blockings (D'Andrea et al., 1998) or less credible thermohaline circulations in the North Atlantic (Thorpe, 2005). Therefore it is worthwhile to analyse European circulation statistics and their relation with precipitation and temperature statistics in more detail. For the simulation of climate change, the simulated changes in the atmospheric circulations, and their impact on temperature and precipitation changes, may be important as well.

For the description of regional circulation statistics we use three geostrophic flow indices: the two components of the geostrophic wind and the geostrophic vorticity. Variations in such flow indices have been shown to correlate well with variations in monthly mean temperature and precipitation (Turnpenny et al., 2002; van Oldenborgh and van Ulden, 2003). In Sect. 3 we compare 20th century model simulations of these flow indices with observations in Central Europe. In addition, we compare observed relations between circulation on the one hand, and temperature and precipitation on the other hand with the corresponding relations in the model simulations. This serves as a further test on the internal consistency of the model simulations. This analysis provides also an estimate of the contribution of biases in simulated circulations to biases in mean temperature and mean precipitation.

In Sect. 4 we analyse simulated changes in the atmospheric circulation, primarily for the SRES A1B emission scenario. Using the techniques developed in Sect. 3, we estimate the contribution of mean circulation changes to changes 
Table 2. Quality of 20th century simulations of mean sea level pressure fields on global and regional scales. The observed fields are mean fields taken from ERA-40. In the bottom row ERA-40 is compared with an analysis based on a long observation record for Europe (Jones et al., 1999). For the models the long-term mean fields from the 20th century simulations were used, including all ensemble members. The spatial correlation and the explained spatial variance were computed separately for each month. The table lists the mean of the twelve monthly values.

\begin{tabular}{|c|c|c|c|c|c|c|c|c|c|c|}
\hline \multirow{4}{*}{$\begin{array}{l}\text { Short } \\
\text { Model } \\
\text { Name }\end{array}$} & \multicolumn{5}{|c|}{ Mean Spatial Correlation $r$} & \multicolumn{5}{|c|}{ Mean Explained Spatial Variance $E$} \\
\hline & Globe & Trop. & S.Lat. & N.Lat & Europe & Globe & Trop. & S.Lat. & N.Lat & Europe \\
\hline & $90^{\circ} \mathrm{S}-$ & $30^{\circ} \mathrm{S}-$ & $30^{\circ} \mathrm{S}-$ & $30^{\circ} \mathrm{N}-$ & $30^{\circ} \mathrm{W}-40^{\circ} \mathrm{E}$ & $90^{\circ} \mathrm{S}-$ & $30^{\circ} \mathrm{S}-$ & $30^{\circ} \mathrm{S}-$ & $30^{\circ} \mathrm{N}-$ & $30^{\circ} \mathrm{W}-40^{\circ} \mathrm{E}$ \\
\hline & $90^{\circ} \mathrm{N}$ & $30^{\circ} \mathrm{N}$ & $90^{\circ} \mathrm{S}$ & $90^{\circ} \mathrm{N}$ & $35^{\circ} \mathrm{N}-65^{\circ} \mathrm{N}$ & $90^{\circ} \mathrm{N}$ & $30^{\circ} \mathrm{N}$ & $90^{\circ} \mathrm{S}$ & $90^{\circ} \mathrm{N}$ & $35^{\circ} \mathrm{N}-65^{\circ} \mathrm{N}$ \\
\hline BCCR2 & 0.84 & 0.95 & 0.79 & 0.73 & 0.75 & 0.70 & 0.88 & 0.63 & 0.35 & 0.58 \\
\hline $\mathrm{BCC}$ & 0.39 & 0.48 & 0.28 & 0.03 & -0.44 & 0.20 & 0.25 & 0.12 & -0.30 & -0.70 \\
\hline CCSM3 & 0.92 & 0.94 & 0.95 & 0.72 & 0.91 & 0.65 & 0.83 & 0.79 & -0.38 & -1.07 \\
\hline CCC47 & 0.92 & 0.92 & 0.88 & 0.87 & 0.93 & 0.83 & 0.76 & 0.74 & 0.54 & 0.71 \\
\hline CCC63 & 0.95 & 0.92 & 0.94 & 0.89 & 0.95 & 0.86 & 0.77 & 0.80 & 0.64 & 0.75 \\
\hline CNRM3 & 0.67 & 0.94 & 0.56 & 0.79 & 0.81 & 0.45 & 0.86 & 0.28 & 0.51 & 0.55 \\
\hline CSIRO3 & 0.92 & 0.94 & 0.91 & 0.79 & 0.88 & 0.64 & 0.84 & 0.74 & 0.33 & 0.68 \\
\hline ECHAM5 & 0.97 & 0.96 & 0.97 & 0.91 & 0.95 & 0.93 & 0.91 & 0.93 & 0.78 & 0.75 \\
\hline ECHO & 0.92 & 0.93 & 0.90 & 0.80 & 0.86 & 0.84 & 0.86 & 0.79 & 0.53 & 0.58 \\
\hline FGOALS & 0.91 & 0.92 & 0.91 & 0.71 & 0.73 & 0.79 & 0.84 & 0.80 & 0.22 & 0.40 \\
\hline GFDL2.0 & 0.93 & 0.96 & 0.92 & 0.76 & 0.81 & 0.84 & 0.89 & 0.85 & 0.32 & 0.57 \\
\hline GFDL2.1 & 0.96 & 0.95 & 0.96 & 0.88 & 0.91 & 0.90 & 0.84 & 0.92 & 0.68 & 0.74 \\
\hline GISSaom & 0.63 & 0.92 & 0.57 & 0.79 & 0.87 & 0.22 & 0.85 & -0.12 & 0.52 & 0.69 \\
\hline GISSeh & 0.66 & 0.85 & 0.68 & 0.66 & 0.67 & 0.25 & 0.63 & 0.12 & -0.03 & 0.26 \\
\hline GISSer & 0.71 & 0.86 & 0.75 & 0.58 & 0.56 & 0.35 & 0.64 & 0.30 & -0.30 & 0.09 \\
\hline INM3.0 & 0.92 & 0.93 & 0.93 & 0.77 & 0.83 & 0.83 & 0.82 & 0.84 & 0.34 & 0.31 \\
\hline IPSL4 & 0.42 & 0.91 & 0.36 & 0.60 & 0.79 & -0.65 & 0.78 & -1.56 & -0.38 & 0.44 \\
\hline MIROChi & 0.93 & 0.94 & 0.91 & 0.88 & 0.93 & 0.74 & 0.88 & 0.80 & 0.70 & 0.84 \\
\hline MIROCm & 0.92 & 0.93 & 0.89 & 0.84 & 0.90 & 0.79 & 0.83 & 0.77 & 0.58 & 0.68 \\
\hline MRI2.3.2 & 0.92 & 0.95 & 0.92 & 0.76 & 0.87 & 0.83 & 0.90 & 0.83 & 0.32 & 0.71 \\
\hline PCM & 0.87 & 0.85 & 0.85 & 0.83 & 0.87 & 0.57 & 0.49 & 0.37 & 0.35 & -0.26 \\
\hline HadCM3 & 0.92 & 0.93 & 0.92 & 0.72 & 0.86 & 0.74 & 0.80 & 0.81 & 0.27 & 0.66 \\
\hline HadGEM & 0.94 & 0.95 & 0.91 & 0.88 & 0.93 & 0.80 & 0.84 & 0.78 & 0.71 & 0.78 \\
\hline Observed & & & & & & & & & & \\
\hline 1780-1995 & & & & & 0.99 & & & & & 0.97 \\
\hline
\end{tabular}

in temperature and precipitation. This is an important issue in the development of regional climate change scenarios, as has been shown by Jylhä et al. (2004). We also explore the changes in the distributions of monthly mean temperature and precipitation. In Sect. 5 we present our conclusions.

\section{Global and regional patterns of long-term mean sea level pressure}

In this section we analyse global patterns of sea level pressure for each month of the year. For the validation of simulated mean sea level pressure patterns we use data from ERA-40 (Uppala et al., 2005). In a recent paper Bromwich and Fogt (2004) found that ERA-40 was not well constrained on a daily basis by observations in data-sparse regions of the southern hemisphere during the pre-satellite era. Despite this, the climatology of ERA-40 appeared to be good, even in this period. Therefore we used the full ERA-40 data set for our test of the model simulations. Using ERA-40 data has the added advantage that it deals with orography in a similar manner as climate models do. There is therefore no reason to exclude mountainous regions from the comparison.

From the model simulations we used the average of all available members of the 20th century runs. For each month the ensemble mean patterns were compared with observations for the globe, for the tropics $\left(30^{\circ} \mathrm{S}-30^{\circ} \mathrm{N}\right)$, for southern latitudes $\left(30^{\circ} \mathrm{S}-90^{\circ} \mathrm{S}\right)$, for northern latitudes $\left(30^{\circ} \mathrm{N}-90^{\circ} \mathrm{N}\right)$ and for Europe $\left(30^{\circ} \mathrm{W}-40^{\circ} \mathrm{E}, 35^{\circ} \mathrm{N}-65^{\circ} \mathrm{N}\right)$. The European domain includes Iceland and the Azores and thus comprises the North Atlantic Oscillation signal.

For each domain and for each month we computed the spatial correlation between the simulated SLP fields and ERA40. The monthly correlations were then averaged over the 12 months. These mean correlations are shown in Table 2. We see that many models simulate SLP fields that are highly correlated with the re-analysis. This indicates that many models 

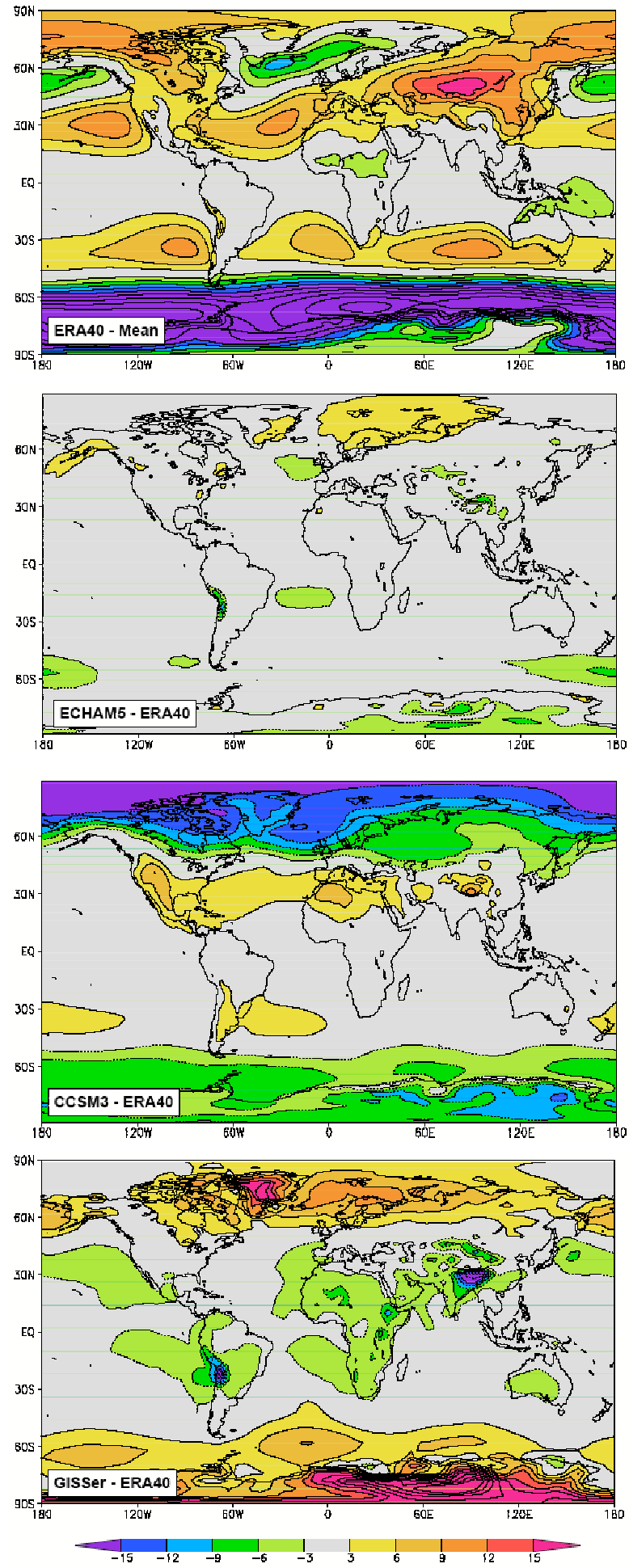

Fig. 1. Mean sea level pressure fields for March 1960-2000. Upper panel: ERA-40 deviations from the global mean pressure. Lower three panels: differences from ERA-40 for ECHAM5, CCSM3 and GISSer. Contour intervals are $3 \mathrm{hPa}$ in all pictures. simulate the positions of the major high pressure and low pressure systems quite well. A more rigourous test is offered by the explained spatial variance $(E)$, which is defined as:

$E=1-\frac{\sigma_{\text {diff }}^{2}}{\sigma_{\mathrm{obs}}^{2}}$

Here, $\sigma_{\text {diff }}^{2}$ is the spatial variance of the difference between simulated and observed long-term mean pressure, and $\sigma_{\text {obs }}^{2}$ the spatial variance of the observed field. This index does not only test the quality of the position of the pressure systems, but also the quality of the amplitude of the pressure variations. Therefore, this index is a better measure for the quality of pressure gradients and of the mean atmospheric circulation than the spatial correlation. We computed the explained variance for each month. By averaging the 12 monthly indices for each region, the annual mean was obtained, which is shown in Table 2. We see that 7 models have a negative skill in at least one of the test domains, while other models have a good performance in all test domains. In order to illustrate the difference between a high and a low skill in the explained variance, we compare in Fig. 1 a few models with ERA-40 for March 1960-2000. The results for this month are characteristic for the other months as well. We see that the simulated pressure field by ECHAM5, which has a high skill, differs little from ERA-40. Also for other months ECHAM5 simulates realistic pressure fields. CCSM3 simulates too low pressures at high latitudes, and too high pressures over the subtropics. As a result, CCSM3 simulates too strong midlatitude westerlies, in particular over the North Atlantic. By contrast, GISSer has a high pressure bias at high latitudes and a low pressure bias over low latitudes. As a result this model simulates too weak mid-latitude westerlies. It should be noted that the dominant scales of these circulation biases are much larger than the scales resolved by the models, and the simulated climate on continental scales will be affected by these biases. CCSM3 and GISSer have a negative skill at northern mid-latitudes, i.e. the variance of the difference field is higher than the spatial variance of the observed field. These results show that a negative skill in explained spatial variance is an indication indeed of severe deviations from the observed pressure fields. For this reason, the seven models with a negative annual mean skill in one of the test domains, were classified as performing poorly.

The 16 remaining models have a positive annual mean skill, in terms of the explained spatial variance. This does not necessarily imply that these models are adequate in all seasons. To investigate this, we consider the annual cycle of the explained variance. It appears that summer circulations at northern latitudes are particularly difficult to simulate correctly. This is shown in Fig. 2 for the simulations by the 16 remaining models. In this figure the models are shown in the order of their annual mean skill over the northern latitude belt as given in Table 2. We see that eight models have a negative skill in one or more months. These models have 


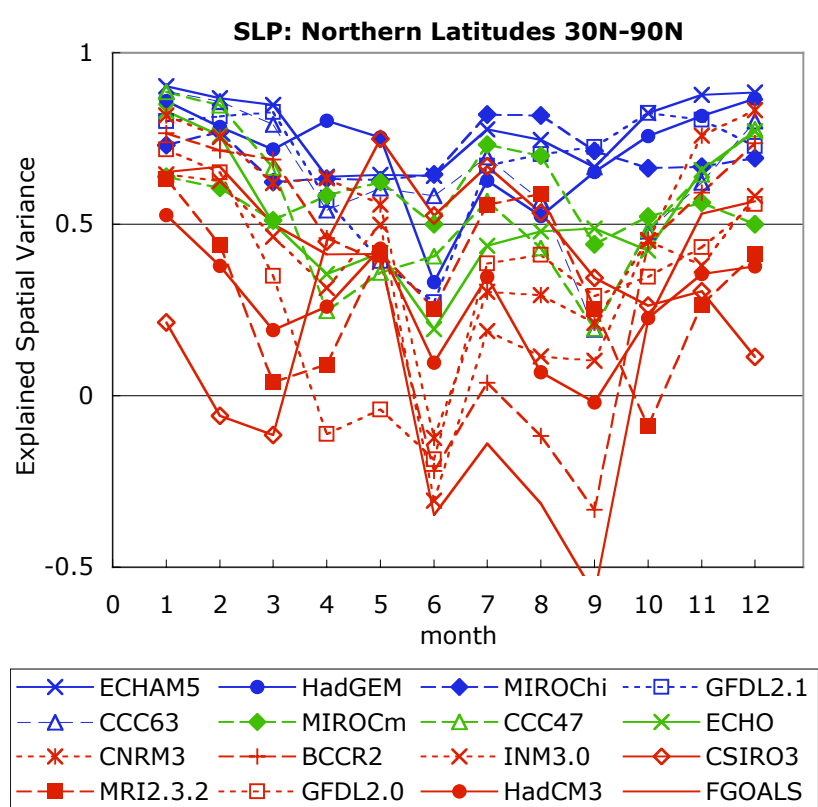

Fig. 2. Explained spatial variance of ERA-40 mean sea level pressure fields for 20 th century simulations by 16 models. Models are listed according to their mean annual skill. Models with a negative skill in one or more months are shown in red. Models with an annual mean negative skill are not shown (see Table 2 and text).

a relatively low annual mean skill as well. The remaining eight models have a positive skill in all months. The top five models (shown in blue) show a promisingly high skill. These are relatively new model versions, which were run at a relatively high resolution. Only CCC63 uses flux corrections at the atmosphere-ocean interface. The next three models are lower resolution versions of one of the top five models, and have a similar behaviour as their high resolution counterparts. For this reason we select the top five models for the detailed European analysis in the rest of this paper. With this selection we do not want to imply that these models are the best models in all aspects of their climate simulations. Selection on the basis of the mean pressure field is just one test of the quality of a model.

We conclude this section with a discussion on natural variability on multi-decadal time scales. In this section we have used ERA-40 to test the models. ERA-40 comprises $45 \mathrm{y}$ of data (Oct 1957-Sep 2002), and may not be representative for the long term mean pressure fields. For Europe we compared the ERA-40 data with the ADVICE pressure reconstruction by Jones et al. (1999), which is directly based on observations and covers the period 1780-1995. It appears that ERA40 explains $97 \%$ of the long-term mean observed spatial variance of the ADVICE analysis (see last row in Table 2). This indicates that the ERA-40 period is quite representative for the long-term mean. In addition we have looked at the natural variability of the European pressure fields by considering
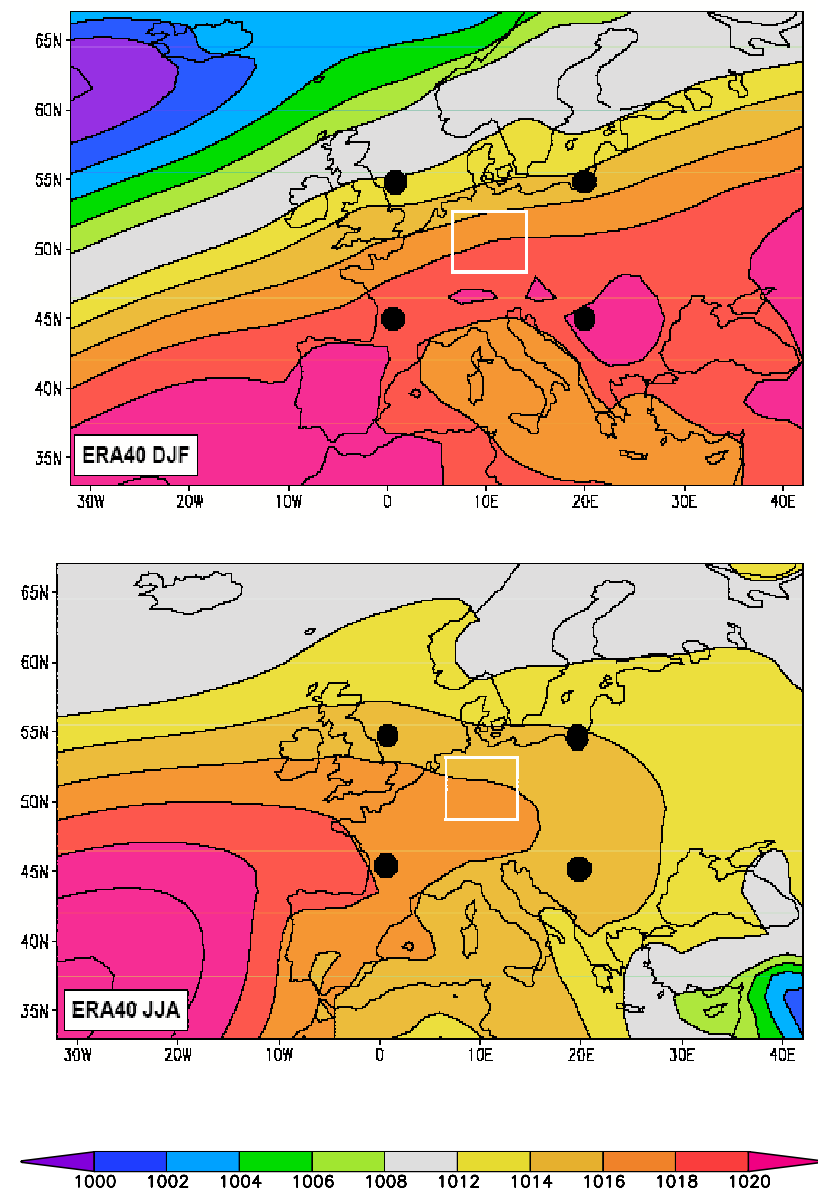

Fig. 3. Observed mean SLP field over Europe. Upper panel: DJF. Lower panel: JJA. The solid circles give the locations of the 4 pressures used to calculate the geostrophic wind components. The squares give the area used for temperature, precipitation and central pressure.

the spatial variance of the difference fields for individual $40 \mathrm{y}$ periods. From these we computed as an estimate of the natural variability on multi-decadal time scales: $\sigma\left(\sigma_{\text {diff }}^{2} / \sigma_{\text {obs }}^{2}\right)$, where $\sigma$ is the standard deviation, $\sigma_{\text {diff }}^{2}$ the spatial variance of the difference field for the different $40 \mathrm{y}$ periods and $\sigma_{\mathrm{obs}}^{2}$ the spatial variance of the long-term mean observed pressure field. It appeared that this metric for natural variability varied from about $1 \%$ for winter months to 5\% in April and May. Averaged over the year this number was about $1 \%$. This implies that natural variability on multi-decadal time scales is weaker than the biases we found between models and observations.

Outside Europe no long observation records were available. Therefore, we applied a similar analysis to individual $40 \mathrm{y}$ periods from the large ensemble of ECHAM5 simulations. For Europe we found that the natural variability on multi-decadal time scales in the model simulation was similar to the observed variability. For the globe and for the three 

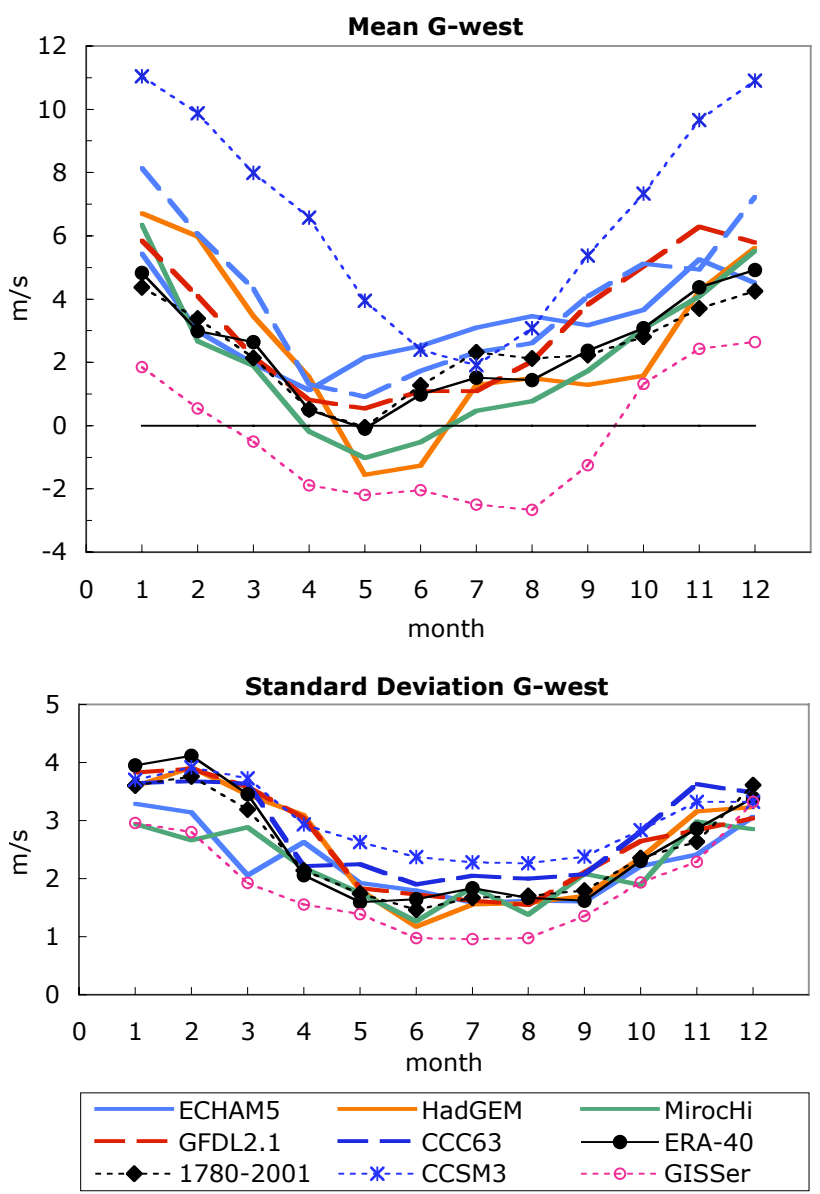

Fig. 4. Observed and simulated west-component of the geostrophic wind.

latitude belts we found a natural variability less than $1 \%$ as an average over the year. These results imply that natural variability plays a minor role in the selection procedure followed above, because biases in the models are much larger than potential biases due to natural variability.

\section{The 20th-century climate in Central Europe}

\subsection{Observations and models}

Our test domain in Central Europe is shown in Fig. 3, together with the mean observed pressure fields in winter and in summer. The domain is situated north of the Alps. The climate is under the influence of prevailing westerlies and moderately maritime. The geostrophic flow indices were computed in the area $0^{\circ}-20^{\circ} \mathrm{E}, 45^{\circ}-55^{\circ} \mathrm{N}$. The geostrophic wind components $G_{\text {west }}$ and $G_{\text {south }}$ were computed from the sea level pressures at the four corners of the domain, using a fixed value for the air density $\left(1.2 \mathrm{kgm}^{-3}\right)$. For the geostrophic vorticity $\left(G_{\text {vorticity }}\right)$ we used the difference between the mean pressure at the four corners of the domain and the mean pressure in the central test domain $\left(6^{\circ}-14^{\circ} \mathrm{E}, 48.50^{\circ}-53.50^{\circ} \mathrm{N}\right)$
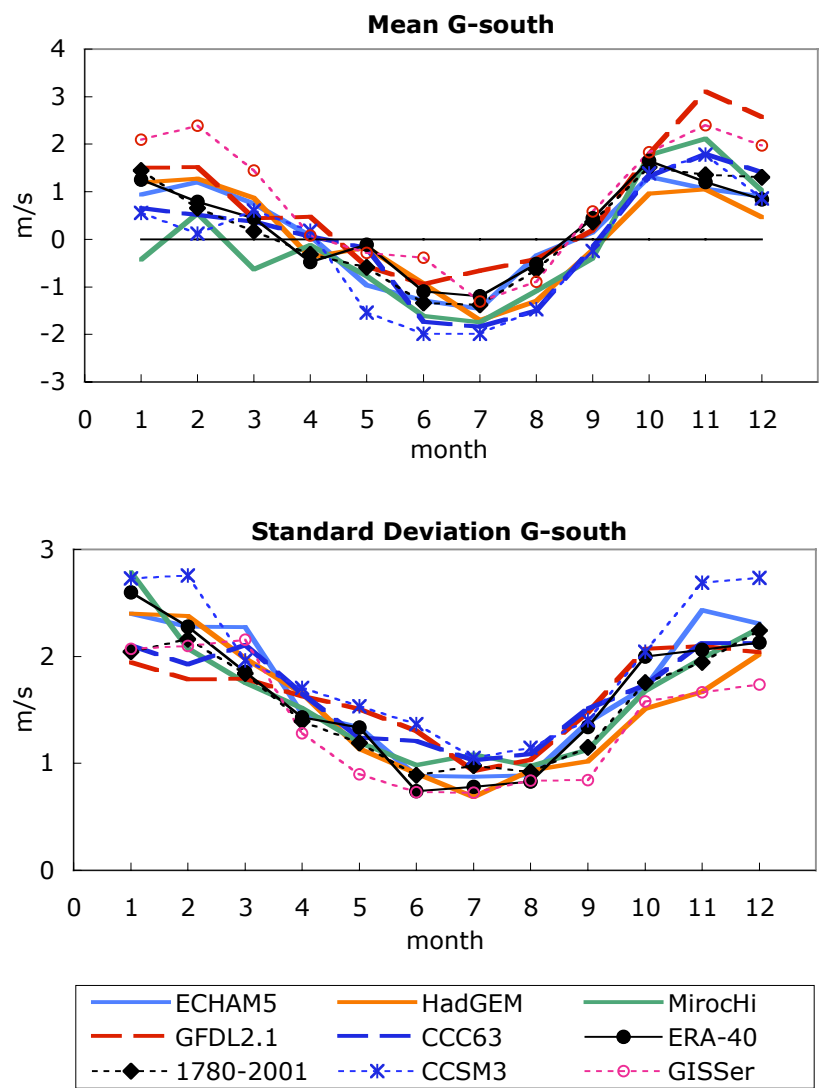

Fig. 5. Observed and simulated south-component of the geostrophic wind.

as a simple proxy. The locations of the centre of the domain and of its four corners are away from major orography, and details of procedures for the reduction of surface pressure to sea level do not play an important role. Monthly mean ERA40 data specified on a $1.5^{\circ} \times 1.5^{\circ}$ grid were used as observations, and interpolated to the analysis points specified above. The ADVICE pressure analysis for 1780-1995 Jones et al. (1999) was used to compare the recent circulation statistics with those of this long observation period. This analysis has a much lower resolution than ERA-40 and is specified on a $5^{\circ} \times 10^{\circ}$ grid. This implies that some of the variability in the geostrophic flow indices may be smoothed relative to ERA40. We tested this for the overlapping period 1958-1995 and found that the standard deviations of $G_{\text {west }}$ and $G_{\text {south }}$ were about 5\% less than for ERA-40. The standard deviation of $G_{\text {vorticity }}$ was about $20 \%$ less than for ERA-40. The higher sensitivity of $G_{\text {vorticity }}$ to smoothing is due to the fact that is based on pressure differences over half the distance as was used for $G_{\text {west }}$ and $G_{\text {south }}$. In order to make the ADVICE time series comparable to those from ERA-40, we applied a linear upscaling to the anomalies in the circulation indices based on the ADVICE analysis. Next we combined ERA-40 and the adjusted ADVICE indices into a single record covering the period 1780-2001. 

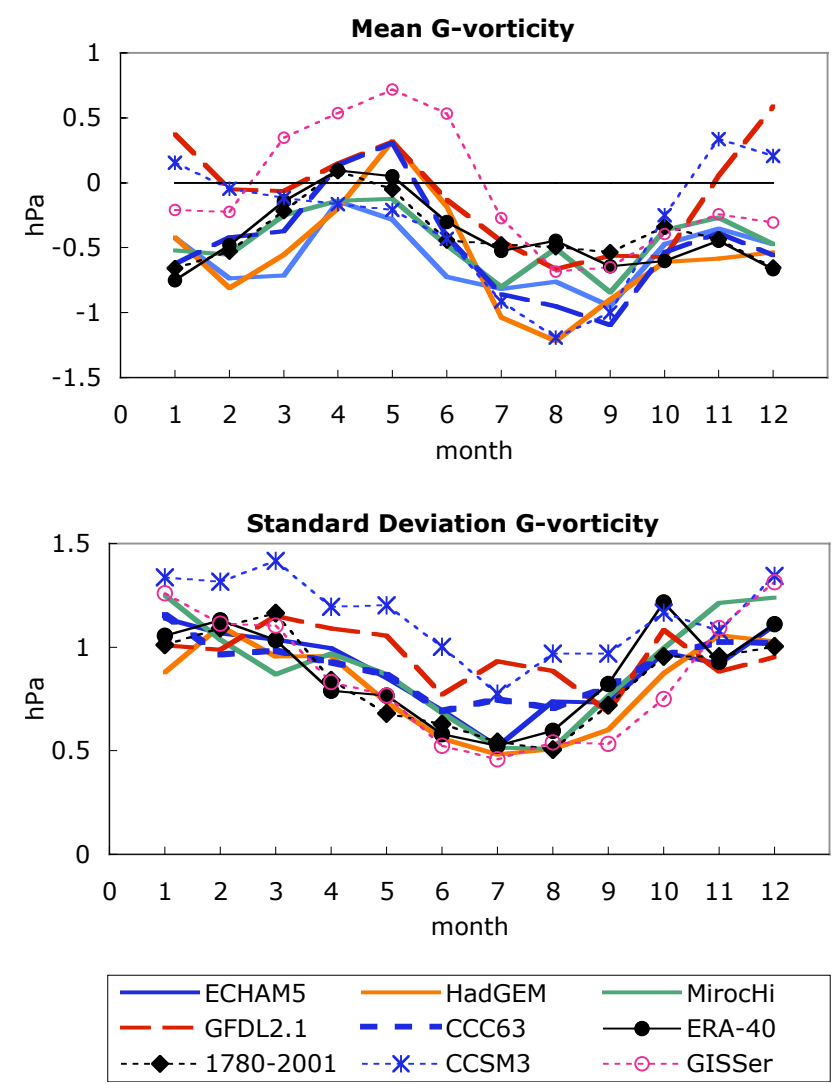

Fig. 6. Observed and simulated geostrophic vorticity.

For temperature and precipitation we used the observed averages over the central test domain. This land domain includes a major part of Germany and smaller parts of adjacent countries. The domain is at a suitable distance from the Alps and is characterised by flat plains and modest orography. Model output was also averaged over this domain. This removes the direct impact of differences in model resolution, which ranges from about $120 \mathrm{~km}$ to $200 \mathrm{~km}$ in Central Europe.

Temperature observations for the period 1960-2000 were taken from the $0.5^{\circ}$ CRUTs 2.0 gridded data set (New et al., 1999, 2000). We also used ERA-40 data for the same period for comparison with the observations.

Precipitation data were also taken from New et al. (1999, 2000). This data set was not corrected for undercatchment due to snow and wind. In order to obtain an estimate of this undercatchment, we compared the New et al. data with a detailed calibrated precipitation data set for the German part of the river Rhine basin (van den Hurk et al., 2005). This data set covers most of the western half of our test region and is available for 1961-1995. In the overlapping domain and overlapping time period, the monthly mean precipitation of the two data sets were highly correlated $(r=0.95)$. The comparison indicated a significant undercatchment in the New et al. data set, ranging from about $2 \%$ in summer months to
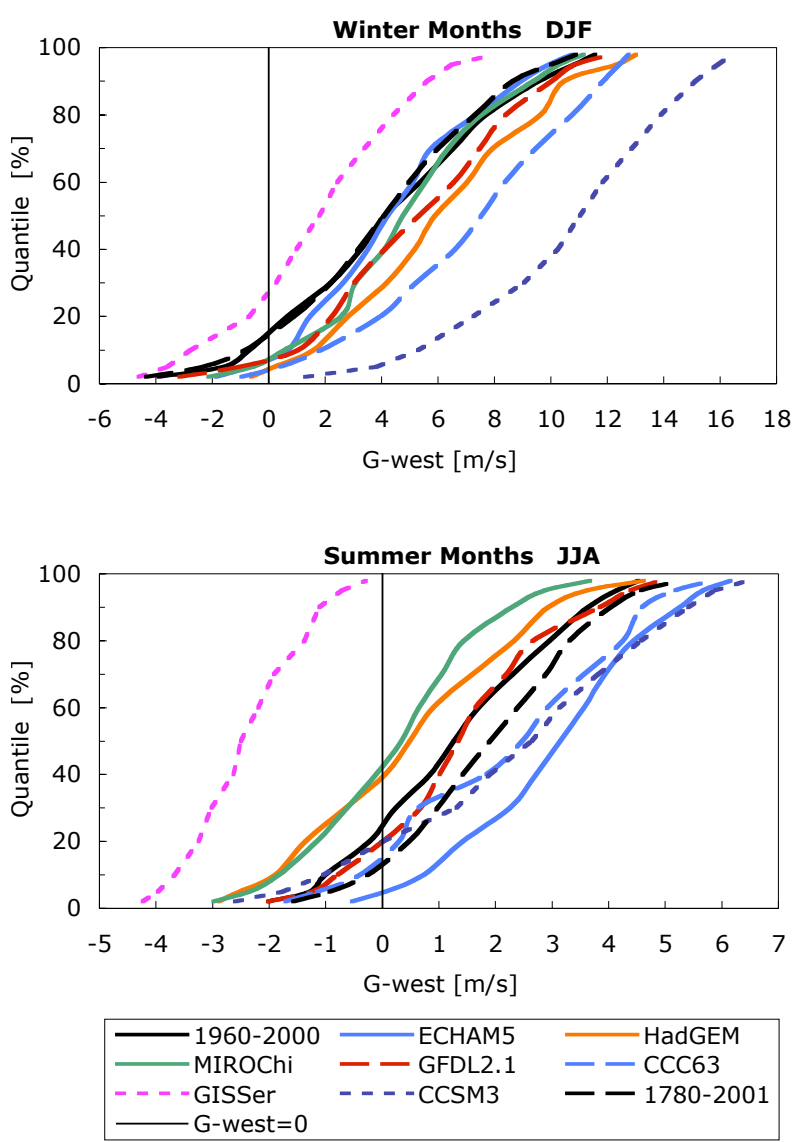

Fig. 7. Cumulative frequency distributions of monthly mean $G_{\text {west }}$. Quantiles were computed as $Q_{i}=100(i-0.5) / n$, were $i$ is the rank number of the month and $n$ the total number of months. For the control period $n=123$ and for the long observation record $n=666$. The distributions were smoothed with a 5 point binomial filter. Shown are quantiles from $2 \%$ to $98 \%$.

$20 \%$ in winter months. We corrected the New et al. data using this estimate of undercatchment in our full test domain. We also used ERA-40 precipitation data for comparison, taking the $12-24 \mathrm{~h}$ precipitation forecasts for this purpose in order to reduce spin-up problems.

For the model assessment given hereafter we used the 5 models selected in the previous section. From the model runs we used the period 1960-2000 from the 20th century run corresponding to the longest run for the A1B stabilisation scenario.

3.2 Geostrophic flow statistics in the control period 1960 2000

In Fig. 4 we show the mean and the standard deviation of $G_{\text {west }}$ for the control period 1960-2000. The observations show a pronounced annual cycle. The mean $G_{\text {west }}$ varies from about $4.5 \mathrm{~m} / \mathrm{s}$ in January to a vanishing mean value in May. The standard deviation varies from about $4 \mathrm{~m} / \mathrm{s}$ in 
February to about $1.5 \mathrm{~m} / \mathrm{s}$ in June. The control period closely matches the data from the long observation record, but shows some interesting differences. The westerlies in the control period are somewhat stronger and more variable in winter. This is due to relatively strong westerlies in recent decades. In July and August the westerlies are clearly weaker in the control period than in the long observation record. This is related to a gradual weakening of westerlies during these months over the 20th century.

The five selected models simulate the observed annual cycle in $G_{\text {west }}$ quite realistically, in the sense that biases are not more than about one standard deviation. With respect to the standard deviation these models are realistic as well, although ECHAM5 and MIROChi underestimate the variability in late winter. For comparison, we included also the simulations by two models with a low skill in global pressure patterns (see Fig. 1 and Table 2). Indeed, we see that these models deviate much more from the observations than the five models with high skill. CCSM3 simulates too strong westerlies in most months, except in summer. The bias is about two standard deviations. GISSer simulates very weak westerlies. In fact this model produces mean easterlies in most months. In summer this model has a bias of more than two standard deviations.

Fig. 5 gives the data for $G_{\text {south }}$. We see that all models are fairly close to the observations. In Fig. 6 we present the geostrophic vorticity. Most models simulate realistic statistics. Mean biases are in general not more than about one standard deviation. GFDL2.1 simulates clearly higher standard deviations in many months.

From these results it appears that the simulation of proper $G_{\text {west }}$ statistics is more difficult than a proper simulation of the other flow indices. The strength and variability of $G_{\text {west }}$ is important because stronger westerlies bring a more maritime climate, while weak westerlies, and in particular months with a mean flow from the east produce rather continental conditions with cold and dry weather in winter and dry and warm weather in summer. Therefore we show the frequency distributions of $G_{\text {west }}$ in Fig. 7 .

For winter months the strong westerly bias for CCSM3 is apparent. This model simulates no months with a mean flow from the east, while in the observations this occurs in about $15 \%$ of the months. GISSer simulates a mean easterly flow in about $25 \%$ of the months. The other models all underestimate the frequency of months with a mean flow from the east, and therefore the frequency of cold and dry winter weather.

In summer the distributions of $G_{\text {west }}$ are clearly different for the control period and for the long record. We see that GISSer simulates extremely continental circulations, without any month with a mean flow from the west. The other models show both stronger than observed and weaker than observed westerlies. ECHAM5 produces very few months with a mean flow from the east, while HadGEM and MIROChi simulate too many of such months. The impacts of these biases on simulated temperatures and precipitation are discussed in the next sections.

\subsection{Relations between circulation variations and tempera- ture variations}

The observed mean annual cycle of the temperature in our test domain runs from around $0^{\circ} \mathrm{C}$ in January to about $17^{\circ} \mathrm{C}$ in July. Fractional snow cover is normal in winter, but complete snow cover is only observed intermittently. The standard deviation of monthly mean temperatures varies between about $3^{\circ} \mathrm{C}$ in winter months to about $1^{\circ} \mathrm{C}$ in summer months. Inter-annual variability of the atmospheric circulation is a prime source for this variability in monthly mean temperature (Turnpenny et al., 2002; van Oldenborgh and van Ulden, 2003). Relations between circulation on the one hand, and temperature and precipitation on the other hand, can be used to analyse the influence of differences in circulation statistics on temperatures and precipitation.

For the description of the influence of the circulation on temperature, we use a simple linear model. Monthly Circulation Temperature Anomalies (CTA) are defined as:

$\mathrm{CTA}=A_{W} \Delta G_{\text {west }}+A_{S} \Delta G_{\text {south }}+A_{V} \Delta G_{\text {vorticity }}+M$

where $\Delta G_{\text {west }}, \Delta G_{\text {south }}$ and $\Delta G_{\text {vorticity }}$ are circulation anomalies relative to the mean observed values for 1960 2000 and where $M$ is a memory term for past circulations. This term is modelled as an exponentially decaying memory with $\tau$ as $e$-folding period. We retained the memory for the circulation in the previous 3 months. Monthly values of the numerical coefficients $A_{W}, A_{S}, A_{V}$ and the memory $\tau$ were obtained from a least-square fit to the observations in 1960-2000, using an iterative estimation procedure. We then multiplied the numerical coefficients by a scaling factor, such that the monthly CTA had the same variance as the observed temperatures. Thus CTA is a variance conserving regression to the observations.

For the models, the circulation anomalies (relative to the mean observed flow indices) are computed from modelled values of $\Delta G_{\text {west }}, \Delta G_{\text {south }}$ and $\Delta G_{\text {vorticity }}$ using Eq. (2) and the observed values of $A_{W}, A_{S}, A_{V}$ and the memory $\tau$. The variance conserving regression line for simulated temperature anomalies is given by:

$\mathrm{TA}_{\mathrm{Regr}}=\langle\mathrm{TA}\rangle+\lambda_{T}(\mathrm{CTA}-\langle\mathrm{CTA}\rangle)$

Where $\langle T A\rangle$ is the mean simulated temperature anomaly and $\lambda_{T}$ is the temperature sensitivity to circulation variations which is given by

$\lambda_{T}=\sigma_{\mathrm{TA}} / \sigma_{\mathrm{CTA}}$

where $\sigma_{\mathrm{TA}}$ denotes the standard deviation of the modelled temperature anomalies TA and $\sigma_{\mathrm{CTA}}$ the standard deviation 


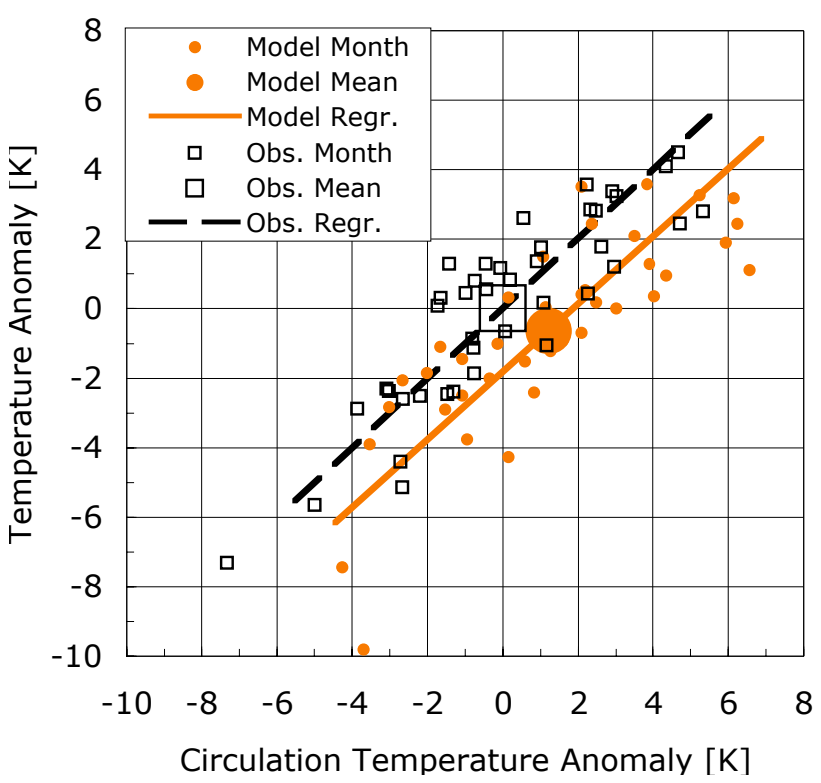

Fig. 8. Illustration of the regression technique and the estimation of circulation related differences for HadGEM for January 1960-2000. In this example the model bias is about $-0.5^{\circ} \mathrm{C}$. There is a warm circulation bias of about $+1.5^{\circ} \mathrm{C}$. The model would have shown a cold bias of $-2.0^{\circ} \mathrm{C}$ if the warm circulation bias had been absent.

of the modelled CTA. The mean temperature bias due to the bias in the simulated circulations is given by

$\mathrm{TA}_{\text {CircBias }}=\lambda_{T}\langle\mathrm{CTA}\rangle$

This estimate of of the temperature bias due to the circulation bias, and similar estimates for temperature changes due to circulation changes later in this paper, are prime applications of the model described by Eqs. (2)-(5). For such applications, it might have been better to use a regression that conserves the mean absolute deviation, instead of the variance. In such an approach the standard deviations in Eq. (4) would have been replaced by the mean absolute deviations and a similar upscaling in the computation of CTA. We have tested this alternative approach and found only minor differences with the model used here.

The analysis procedure described by Eqs. (2)-(5) is illustrated in Fig. 8, which shows scatter plots, means and regression lines of simulated and observed temperature anomalies against circulation temperature anomalies.

This simple model performs quite well for the observations, with correlations around 0.8 (see Fig. 9). In winter and summer, $G_{\text {west }}$ is the dominating term in Eq. (2). In the transition months $G_{\text {south }}$ and $G_{\text {vorticity give the largest contri- }}$ bution to the explained variance. The memory length is typically 0.5 to 1 month. The contribution of the memory term to the explained variance is most significant in late winter (memory for snow feedback) and in late summer (memory for soil moisture depletion). Nearby seas produce memory
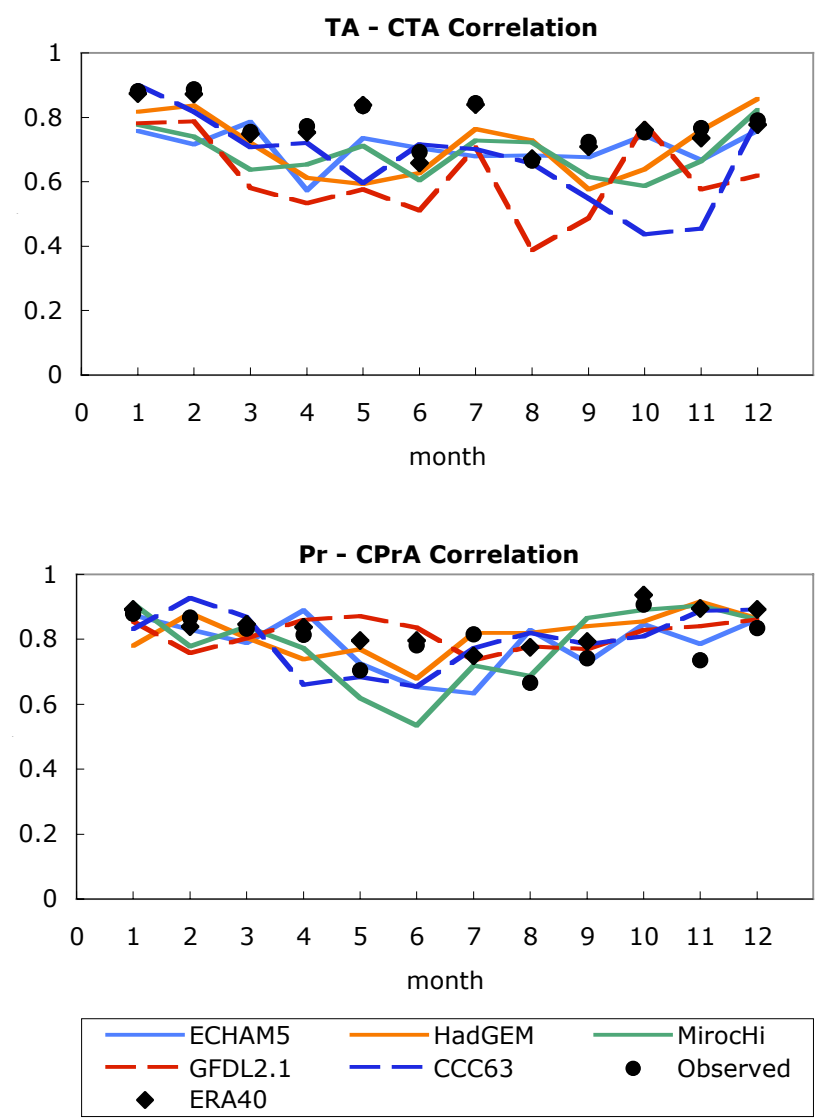

Fig. 9. Correlations between monthly mean anomalies of the circulation indices and the monthly mean anomalies in temperature and precipitation.

effects all year round. Fig. 9 also shows the monthly correlations between temperature and circulation for the five models. In winter, all models show high correlations, similar to the observed correlations. In summer, some models show somewhat lower than observed correlations. We have included temperature simulations from ERA-40 as well. Since surface air temperatures over land were not assimilated in ERA-40, this serves as an intermediate test on the ability of the re-analysis model to simulate surface air temperatures in a realistic manner. ERA-40 temperatures appear to be almost identical to the observations.

A second factor which describes the correspondence between the models and the observations is the sensitivity factor $\lambda_{T}$ which is defined in Eq. (4). For the observations $\lambda_{T}=1$ by definition. For the models $\lambda_{T}$ differs less than $20 \%$ from unity for most months. In January and December, the sensitivity of MIROChi and CCC63 is about 30\% smaller than observed. In general the correlations and sensitivities are satisfactory. Later, we will discuss observed and modelled temperature distributions.

First we look at biases in the mean temperature. In Fig. 10 we show the total temperature bias in the model simulations 

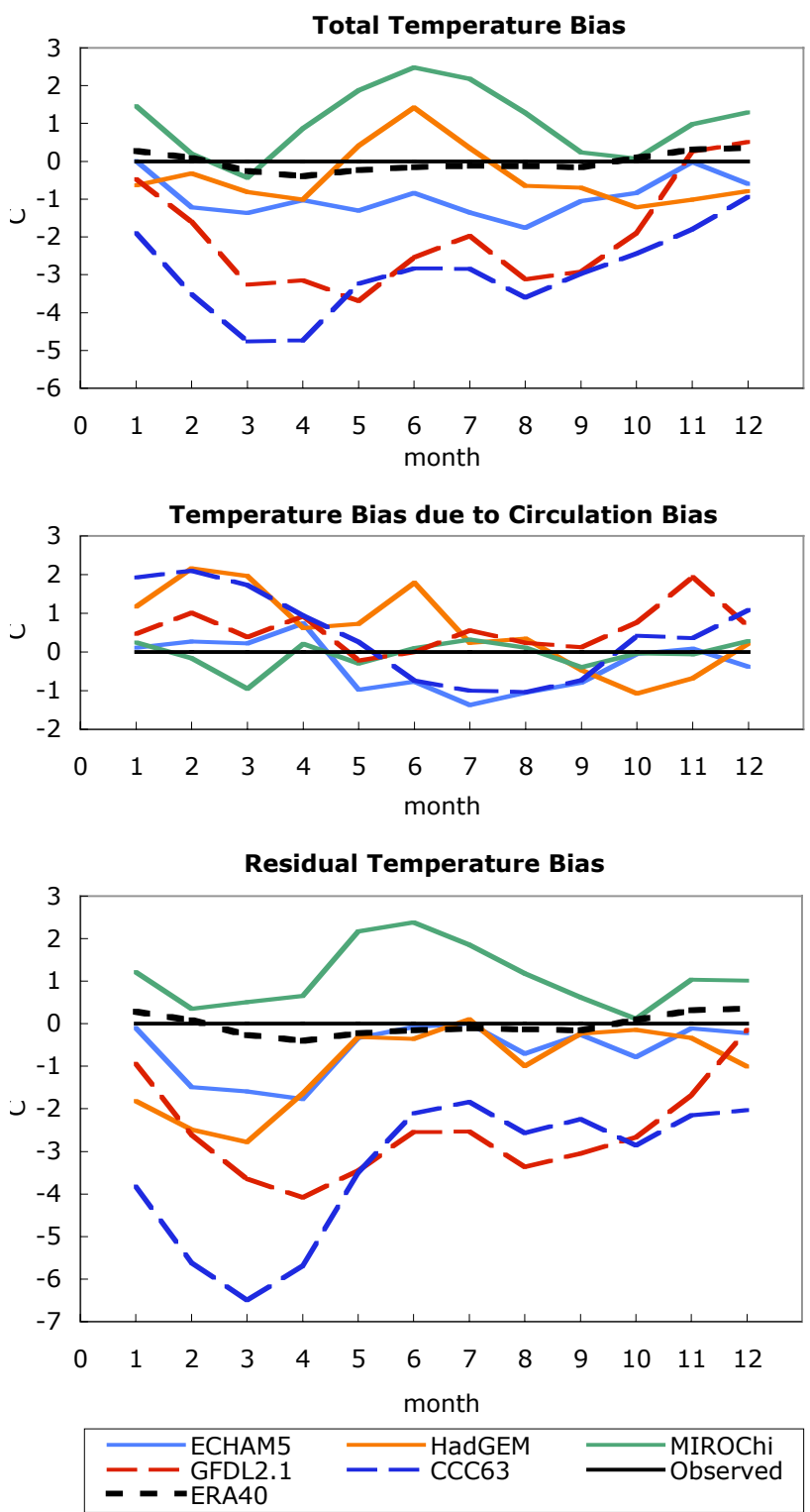

Fig. 10. Temperatures biases; 1960-2000.

(upper panel), the temperature bias attributable to circulation biases (middle panel) and the residual temperature bias (lower panel), which is obtained by subtracting the circulation induced bias from the total bias. We see that the temperature bias due to the circulation bias shows a modest range between $-1^{\circ} \mathrm{C}$ and $+2^{\circ} \mathrm{C}$. For models with a larger circulation bias this temperature bias can be much larger (not shown). The residual temperature bias ranges from about $-6^{\circ} \mathrm{C}$ to $+2^{\circ} \mathrm{C}$. Overall, GFDL2.1 and CCC63 have a strong cold bias, in particular in March and April. This cold bias is also present in the simulation of the Northern Hemisphere temperatures by these models. The other models have reasonable residual biases.
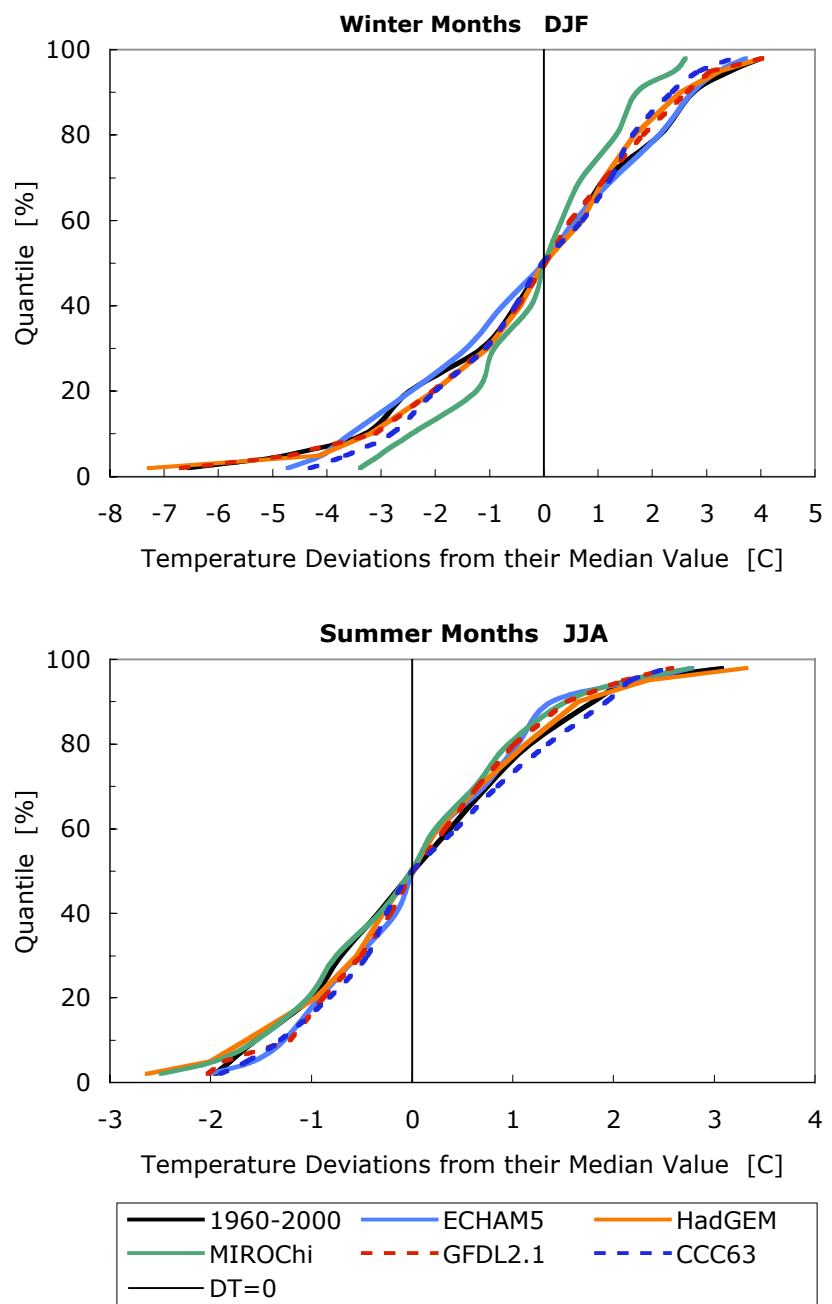

Fig. 11. Observed and simulated frequency distributions of monthly mean temperature deviations from their median value for winter months (DJF) and for summer months (JJA) for the period 19602000

Next we consider the observed and simulated cumulative temperature distributions, which are given in Fig. 11. The top panel shows the distributions for winter months. High temperatures correspond to warm westerlies that bring maritime air to the continent. Low temperatures correspond to cold easterlies that carry continental air to Central Europe, combined with a snow cover. The distributions are negatively skewed, due to a stronger temperature response to circulation variations when the flow is from the east. The distribution of the circulation indices is not skewed (not shown). The total temperature range can be seen as a measure for the difference between maritime and continental temperatures. MIROChi simulates weaker than observed temperature variations. This is due to a weaker than observed variability in circulations (CTA) and a low sensitivity $\left(\lambda_{T}\right)$. The other models simulate the observed distribution quite well, although the models differ considerably in their simulation of cold extremes. 

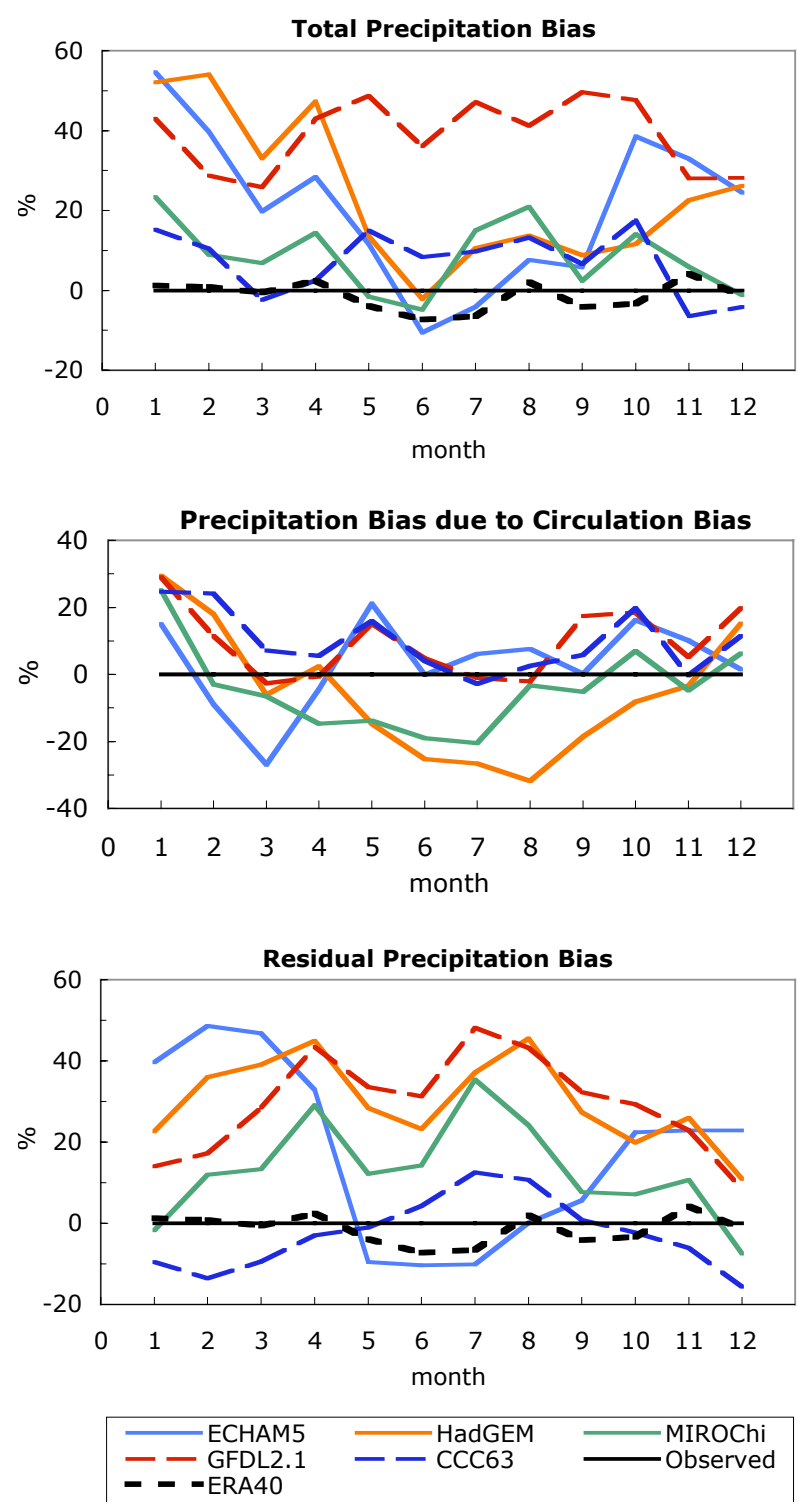

Fig. 12. Precipitation biases: 1960-2000.

The lower panel in Fig. 11 shows the distributions for summer months. The observed distribution is positively skewed, due to a stronger temperature response to circulation variations when the flow is from the east. We see that all models produce realistic temperature distributions in summer. It may be worthwhile to see how the warm summer of 2003 fits into this distribution (Schär et al., 2004). Fig. 11 gives the distribution between $2 \%$ and $98 \%$, and the two highest and two lowest extremes are not shown. The highest extreme observed in the control period was July 1994, with a temperature anomaly of $4.2^{\circ} \mathrm{C}$. For the models the absolute extremes ranged from $3.0^{\circ} \mathrm{C}$ to $3.8^{\circ} \mathrm{C}$. The months June and August of 2003 both had a temperature anomaly of about $4^{\circ} \mathrm{C}$ in our test region. Two of such months in one summer is quite extreme
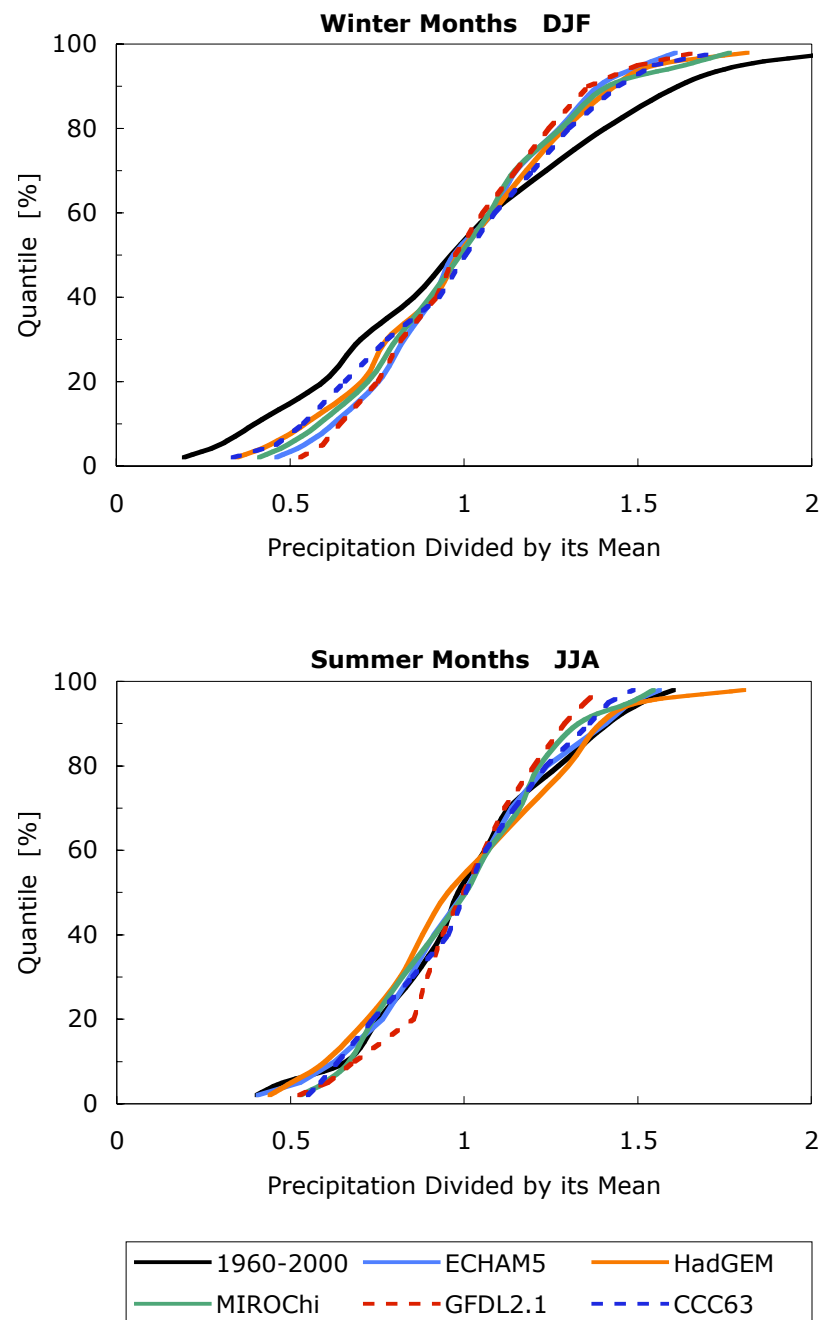

Fig. 13. Distributions of monthly mean precipitation for winter months (upper panel) and for summer months (lower panel) for 1960-2000. Each distribution was scaled with its own mean precipitation.

indeed, but this extreme does not lie far outside the modelled and observed distributions for the control period.

When comparing the results from Fig. 10 and Fig. 11, we conclude that mean biases in temperature simulations are more important than biases in the distribution, except for very cold months in winter.

\subsection{Relations between circulation variations and precipita- tion variations}

The analysis for precipitation is very similar to that for temperature. Circulation Precipitation Anomalies were defined as:

$\mathrm{CPrA}=B_{W} \Delta G_{\text {west }}+B_{S} \Delta G_{\text {south }}+B_{V} \Delta G_{\text {vorticity }}$

This model performs quite well, both for the observations and for ERA-40 and for the climate model simulations (see 

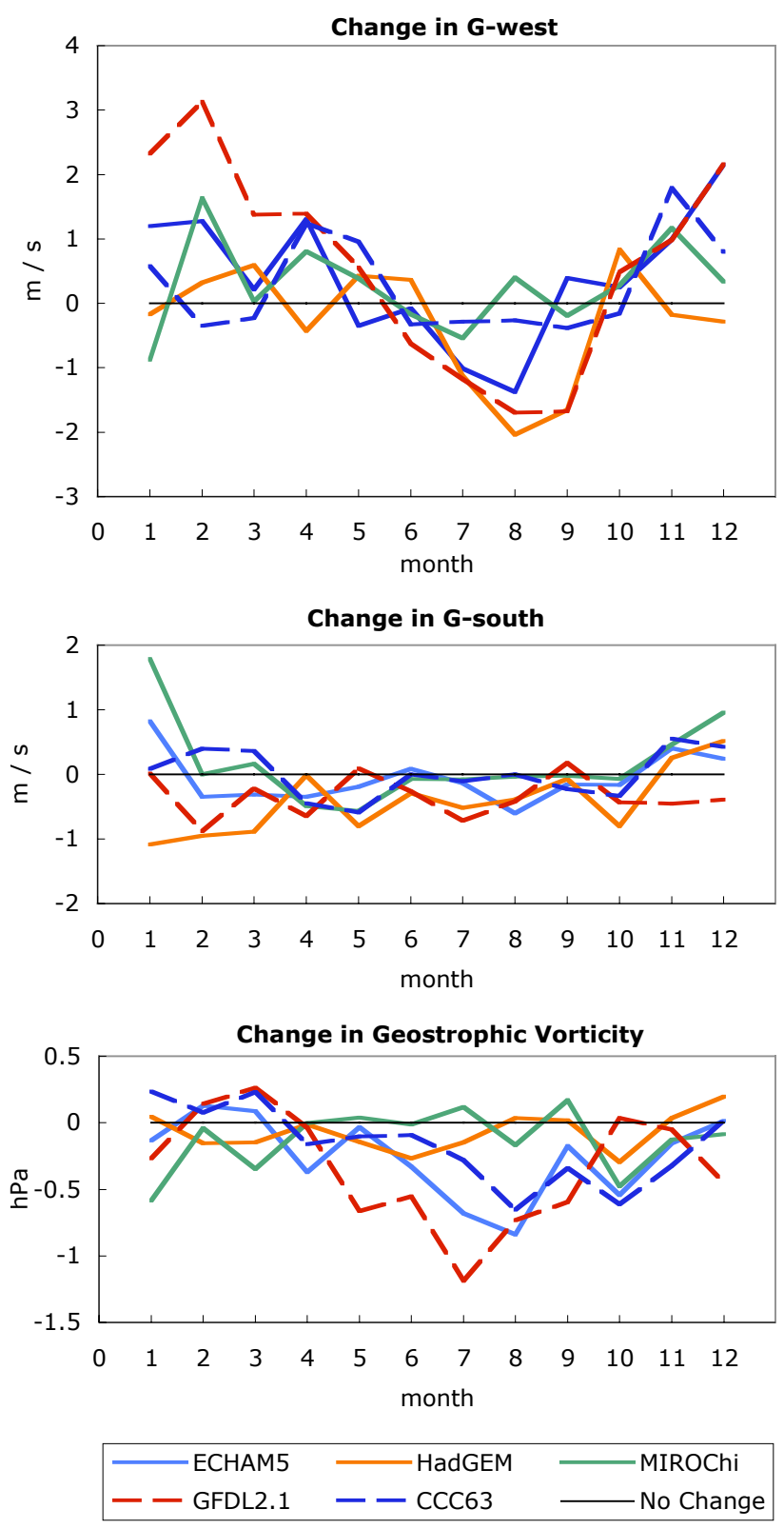

Fig. 14. Changes in geostrophic flow indices from 1960-2000 to 2060-2100 for the A1B scenario.

Fig. 9). $G_{\text {west }}$ and $G_{\text {vorticity }}$ are the most important contributors to the explained variance for all months. We found no memory effects, which is not surprising, because air masses collect their precipitable water from evaporation in very large domains.

Next we look at the mean biases in precipitation. The observed annual mean precipitation is $2.1 \mathrm{~mm} /$ day. It is rather evenly distributed over the year, with a minimum of $1.8 \mathrm{~mm} /$ day in April and a maximum of $2.5 \mathrm{~mm} /$ day in June. In Fig. 12 we show the precipitation biases for the control period. These biases are given as a percentage of the monthly mean observed precipitation. In the upper panel we have included the $12-24 \mathrm{~h}$ precipitation forecasts by ERA-40. We see that this precipitation product is very similar to the observations. For the climate model simulations we see rather large biases: up to about $50 \%$. The biases due to circulation biases are large as well and range from $-30 \%$ to $+30 \%$. The residual biases remain high. HadGEM and GFDL2.1 have a pronounced positive bias throughout the year. MIROChi has a positive bias mainly in spring and in summer. ECHAM5 has a strong annual cycle in its residual bias and produces very wet winters, but realistic summer precipitation. CCC63 is realistic throughout the year.

Figure 13 shows the relative frequency distributions for winter months and for summer months. In winter the simulated variability is too small in a relative sense, which is due to a lower than observed variability of CPrA and a lower than observed precipitation sensitivity to $C P r A$ variations in the model simulations. In summer the relative distributions are fairly realistic. GFDL2.1 simulates weaker than observed variability, while the variability is higher than observed for HadGEM.

From the Figs. 12 and 13 we may conclude that all mean biases are quite large for at least several of the models. Circulation biases are important both for the mean precipitation and for the precipitation distribution in winter.

\section{Climate change in Central Europe for the A1B emis- sion scenario}

\subsection{Changes in atmospheric circulation}

In this section we analyse changes in the atmospheric circulation over Europe for the A1B emission scenario. In this scenario the radiative forcing increases more or less linearly in the 21 st century and is about constant thereafter. We consider differences between the period 2060-2100 and the control period 1960-2000. Simulated changes in the geostrophic flow indices are shown in Fig. 14. Major changes in $G_{\text {west }}$ are simulated in winter (DJF) and in late summer (JAS), although the models differ considerably in their circulation response. GFDL2.1 simulates for the future much stronger westerlies in winter and much stronger easterlies in late summer. HadGEM also simulates much stronger easterlies in late summer. The simulations show much weaker changes in $G_{\text {south }}$, although there is an appreciable range in responses in January. With respect to $G_{\text {vorticity }}$, several models simulate much increased anticyclonic conditions in the summer half year, in particular GFDL2.1. Overall, GFDL2.1 simulates the strongest circulation changes over Central Europe, while MIROChi simulates rather weak changes.

In order to illustrate the differences in the circulation response for these two models, we show the simulated pressure changes over Europe for late summer in Fig. 15. We see that for MIROChi the pressure changes are smaller than $1 \mathrm{hPa}$ 

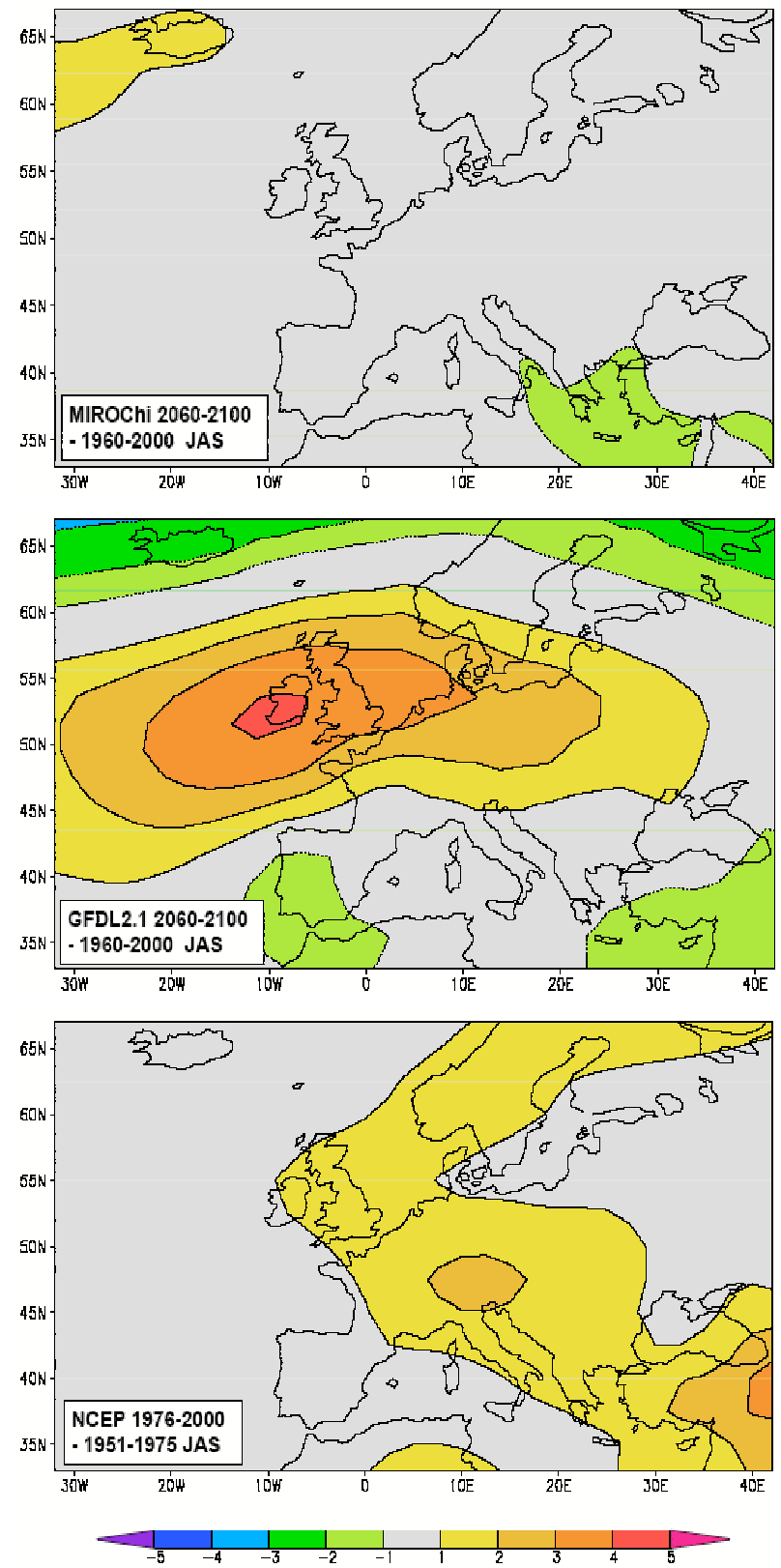

Fig. 15. Changes in sea level pressure over Europe. Contour interval is $1 \mathrm{hPa}$. Upper panels: simulated changes for the A1B scenario. Lower panel: observed changes from 1951-1975 to 19762000 (NCEP re-analysis).

over most of Europe. This holds more or less for ECHAM5 and CCC63 as well (not shown). By contrast, GFDL2.1 simulates pronounced pressure increases over West and Central Europe, with a maximum increase of $4 \mathrm{hPa}$ over Ireland. Over Northern Europe and over Spain and Turkey the mean pressure decreases. These pressure changes enhance westerlies over Northern Europe, and enhance easterlies over Central Europe. The pressure change pattern for HadGEM re-
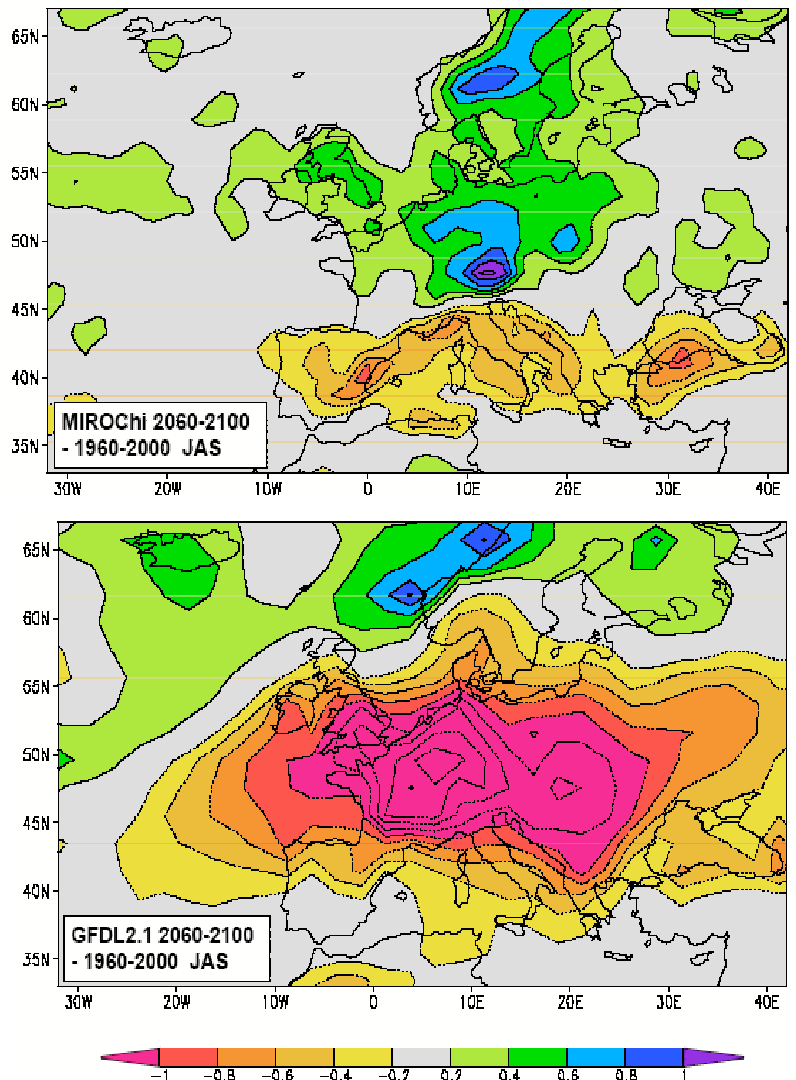

Fig. 16. Changes in precipitation over Europe for the A1B scenario. Contour interval is $0.2 \mathrm{~mm} /$ day. In the purple region the drying is more than $1 \mathrm{~mm} /$ day.

sembles that for GFDL2.1, but it is about $40 \%$ weaker and it is shifted $800 \mathrm{~km}$ to the north-east (not shown).

Recently is has been suggested by Pal et al. (2004) that simulated circulation changes resemble observed changes in the second half of the 20th century. In order to see if this is true for the present model simulations, we show in Fig. 15 the observed changes in sea level pressure for the NCEP reanalysis. We see that the observed pressure change pattern does not resemble the simulated change patterns. This implies that the correspondence between simulated changes and observed changes reported by Pal et al. (2004) may be fortuitous.

The relation between circulation changes and precipitation changes is addressed in the next section.

\subsection{Changes in precipitation}

Figure 16 shows the changes in late summer precipitation for MIROChi and GFDL2.1. The differences between the two models are quite dramatic. MIROChi simulates precipitation increases over Europe north of the Alps, and drying over the Mediterranean region. GFDL2.1 simulates severe drying 

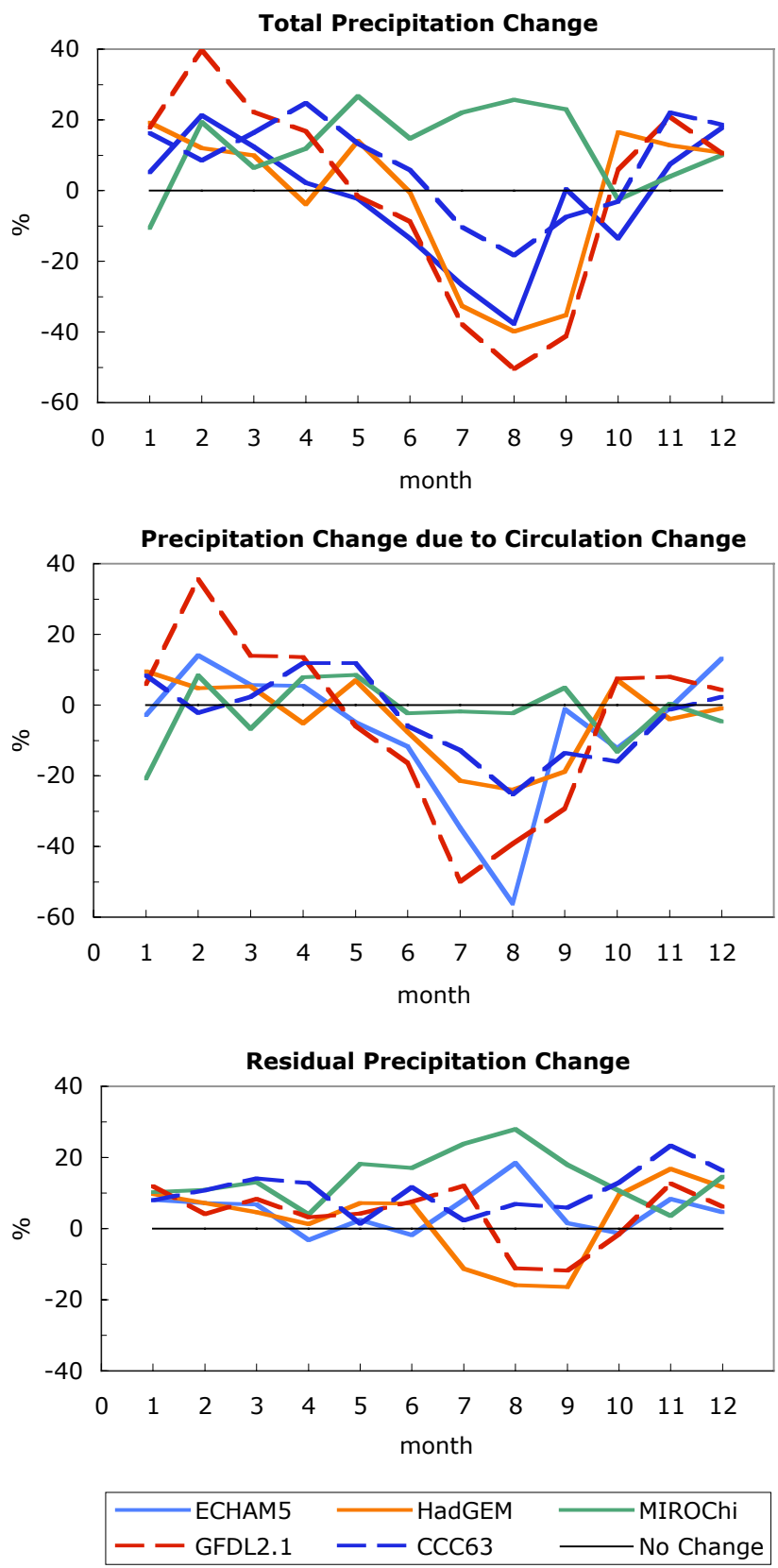

Fig. 17. Changes in precipitation for the A1B scenario. Shown are differences between the scenario period 2060-2100 and the control period 1960-2000.

over Central and Western Europe. Over north-eastern France the precipitation reduction amounts to $1.8 \mathrm{~mm} /$ day. When we compare the drying region with the circulation change in Fig. 15, we see that major drying occurs where enhanced easterlies and more anticyclonic conditions prevail.

In Fig. 17, we quantify the precipitation changes in our test domain for all months. We see precipitation increases in the winter half year, and (except for MIROChi) precipitation reductions in late summer. Also shown are the precipitation

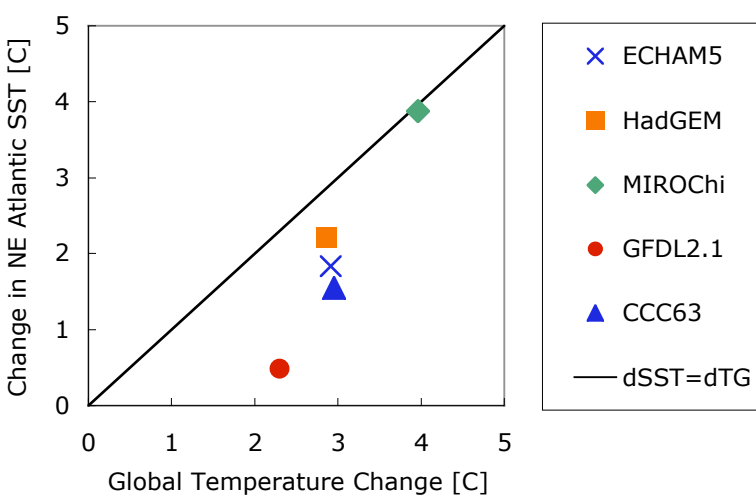

Fig. 18. Global mean temperature changes between the scenario period 2060-2100 and the control period 1960-2000, and corresponding changes in sea surface temperature over the North East Atlantic $\left(40^{\circ} \mathrm{N}-65^{\circ} \mathrm{N}, 40^{\circ} \mathrm{W}-10^{\circ} \mathrm{E}\right)$ for late summer (JAS).

changes due to circulation changes. After removal of the circulation signal, a much more transparent residual signal results. For most months a modest increase in precipitation is shown. In late summer important differences in residual precipitation change remain between the models. We have identified two factors that may have contributed to these differences.

The first factor is the change in sea surface temperature (SST) over the North Atlantic. Since the North Atlantic is a major source of precipitable water in the atmosphere over Europe, differences in SST changes may affect the precipitation over Europe. In Fig. 18 we show the SST changes over the North East Atlantic plotted against the simulated global mean temperature changes. We see marked differences between the models. GFDL2.1 simulates very weak increases in SST, which are $2^{\circ} \mathrm{C}$ less than the global mean temperature changes simulated by this model. The SST change for MIROChi is similar to its global mean change. This indicates that for MIROChi moisture supply by the North Atlantic can keep up with the pace of global warming, while for GFDL2.1 this is not the case. The other models take a middle position between the two extremes. Changes in the North Atlantic thermohaline circulations may play a role here (Hazeleger, 2006; Schmittner et al., 2005), but relations between such changes and SST changes have not been firmly established. A detailed analysis of the origins of the differences between SST simulations would certainly be worthwhile, but falls outside the scope of this paper.

The second factor is soil moisture depletion. GFDL2.1 and HadGEM simulate a strong reduction in precipitation over Central Europe. This may lead to significant soil moisture depletion, which reduces the contribution of land evaporation to precipitable water, and thus further reduce the precipitation simulated by these models. It is not clear whether such a severe drying tendency is realistic. 

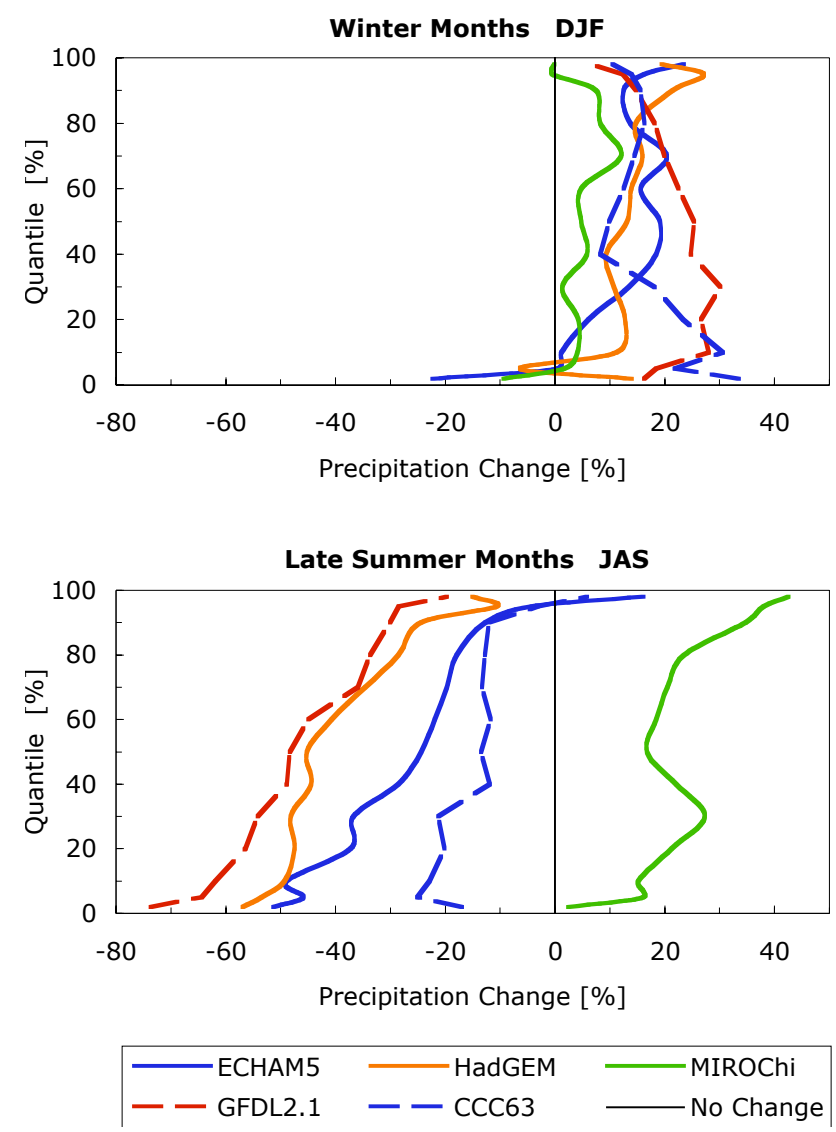

Fig. 19. Changes in precipitation distribution. The relative change is computed as $100\left(\operatorname{Pr}_{f}-\operatorname{Pr}_{c}\right) / \operatorname{Pr}_{c}$, were $\operatorname{Pr}_{f}$ is the future precipitation and $\operatorname{Pr}_{\mathrm{C}}$ is the control precipitation for a given quantile.

In Fig. 19, we show the changes in the precipitation distribution for winter months and for late summer months. Changes for high quantiles give the percentage change for relatively wet months, while the lower quantiles give the changes for dry months. In winter we see similar percentage changes for all quantiles, which implies that changes in the distribution are small. In summer we see more pronounced relative drying in dry months, or less moistening (for MIROChi). Wet months dry less in a relative sense, or show a stronger increase (for MIROChi). In general, the relative variability in late summer precipitation increases for all models. However, the range of absolute changes in the precipitation is so large, that no firm conclusions can be drawn with respect to summer precipitation in a future climate in Europe.

\subsection{Temperature changes}

In Fig. 20, we show the model simulations of temperature changes. For temperature the contributions of circulation changes are in general smaller than the total changes. The residual changes range from less than $2^{\circ} \mathrm{C}$ for GFDL2.1 to
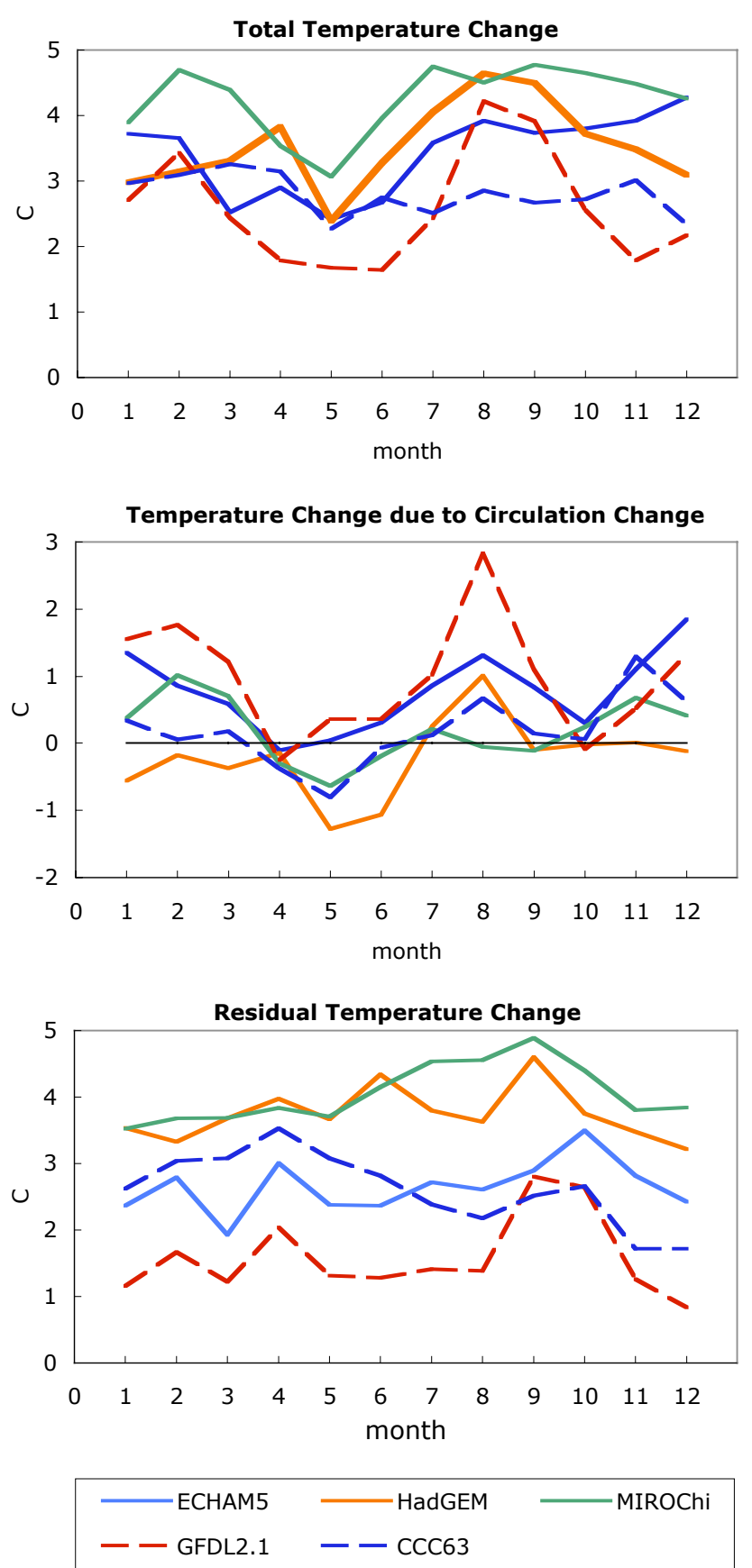

Fig. 20. Temperature changes for the A1B scenario. Shown are differences between the scenario period 2060-2100 and the control period 1960-2000.

about $4^{\circ} \mathrm{C}$ for HadGEM and MIROChi and are close to the global mean temperature changes simulated by each model. More interesting may be the changes in the temperature distributions, which are given in Fig. 21. For winter months HadGEM and GFDL2.1 simulate weaker warming for warm months (high quantiles) and much stronger warming for cold months (low quantiles). This reduces the variability of winter 

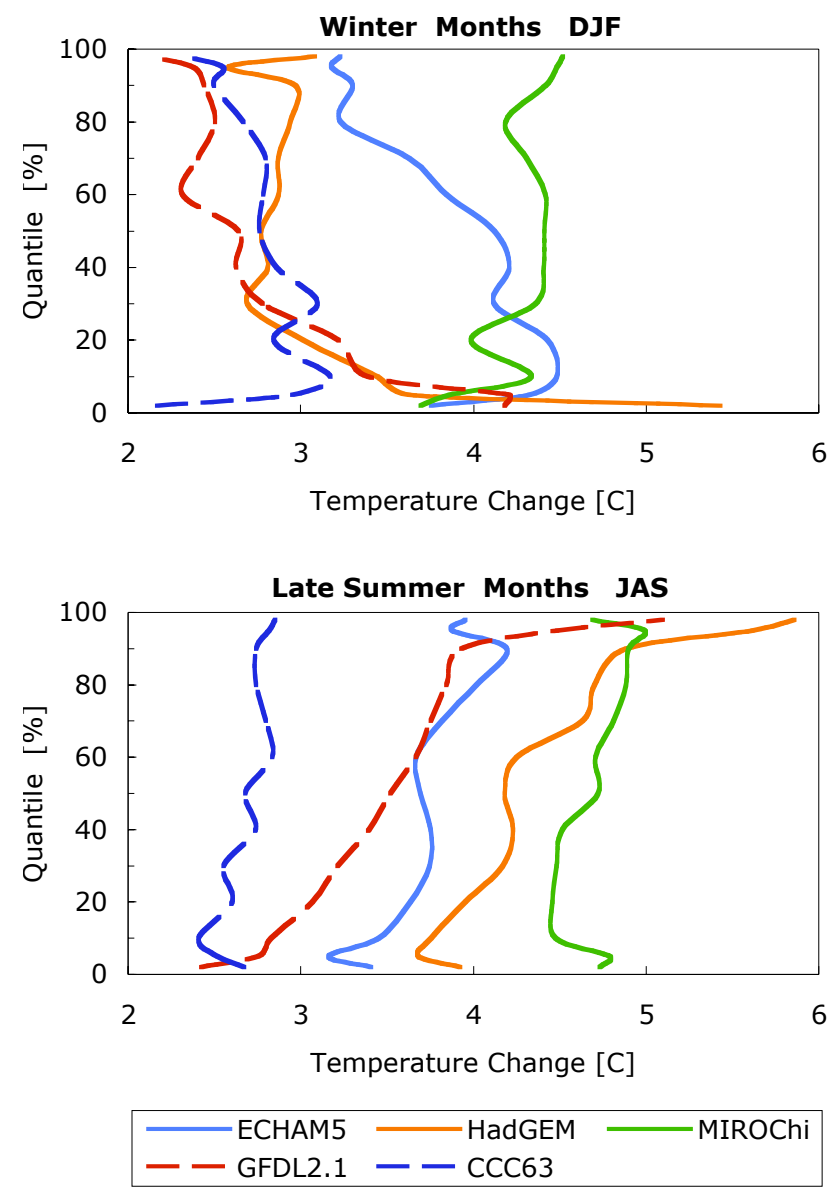

Fig. 21. Changes in temperature distribution.

temperatures considerably. CCC63 and MIROChi show only weak changes in the temperature distributions. ECHAM5 takes a middle position. The range of simulated changes in the temperature distribution is very wide. This illustrates how uncertain model predictions are with respect to these distribution changes in winter.

Next we consider the distribution changes in late summer. Again CCC63 and MIROChi simulate only weak changes in the temperature distribution. ECHAM5 produces a moderate change in this distribution. Major changes are predicted by GFDL2.1 and HadGEM. The highest quantiles in particular, show very large temperature increases. This is probably related to the strong precipitation reduction simulated by these models. This leads to soil moisture depletion, reduction in evaporation and an enhancement of the sensible heat flux. The details of such feedback processes have been discussed in some detail by van den Hurk et al. (2005), Lenderink et al. (2006) and van Ulden et al. (2006). While severe summer drying does occur occasionally in West-Central Europe (for example in 2003), the frequency of such episodes increases considerably for some models, while it does not for other models. This may explain part of the wide range of distribution changes for late summer. Another part is due to differences in SST changes. The strong SST change for MIROChi enhances the temperature change for cold summer months which are characterised by strong westerlies. GFDL2.1 shows a rather modest temperature increase for cold summer months, which is in line with the limited warming of the North Atlantic, and with the low global climate sensitivity shown by this model.

Our analysis of temperature distributions can be summarised as follows. The range of a temperature distribution depends on the difference between continental temperatures, which prevail for strong easterly flow, and maritime temperatures, which prevail for strong westerlies. Changes in the distribution depend both on changes in maritime temperatures, (which depend on the changes in North Atlantic SST) and on changes in continental temperatures (which are influenced by land surface processes, cloudiness and radiation changes). In addition, changes in the circulation lead to an overall shift to a more maritime climate in winter and a more continental climate in late summer. The models show large differences in SST changes in late summer, with changes of $0.5^{\circ} \mathrm{C}$ for GFDL2.1 to $4^{\circ} \mathrm{C}$ for MIROChi. In winter the SST changes are smaller and range from $0.3^{\circ} \mathrm{C}$ for GFDL to $2.3^{\circ} \mathrm{C}$ for MIROChi. Warming of continental temperatures is in general stronger than the warming of North Atlantic SST, but major differences are seen between the models. MIROChi simulates only weak changes in the difference between continental temperatures and SST. GFDL2.1 and HadGEM simulate much stronger increases in the difference between continental temperatures and SST than the other models, both in winter and in late summer. In late summer the strong response of continental temperatures simulated by GFDL2.1 and HadGEM is probably related to severe soil moisture depletion. These models simulate both a strong reduction in precipitation and a strong increase in the temperature difference between land and sea in summer. This increased land-sea temperature contrast might promote changes in the pressure pattern of the type simulated by these models, i.e. higher pressure over the British Isles and lower pressure over Southern Europe. This would create an interesting positive feedback between circulation changes, enhanced easterlies over the continent, enhanced drying and enhanced temperature increases over land. Such positive feedback mechanisms would make the summer climate system highly non-linear, and very sensitive to the treatment of land surface processes and to the modelling of North Atlantic SSTs.

\section{Conclusions}

We have tested 23 coupled climate models with respect to their ability to simulate realistic global patterns of long-term mean monthly sea level pressure. Most models showed high correlations with the observed pressure fields. Many models were less satisfactory with respect to the explained spatial 
variance, and showed negative skills for specific months and latitude belts. This implied a poor simulation of pressure gradients and circulation indices. The bias patterns had very large scales and affect the climate at continental scales and larger. This has implications for regional climate modelling, because regional models inherit the large-scale circulation biases from the global host model that provides the boundary conditions.

Out of 23 global models, five models simulated realistic pressure patterns in all analysed latitude belts for all months of the year, while three models showed a reasonable performance. These eight models simulated realistic circulations over Europe as well.

Simulations by the five models with the best sea level pressure fields were analysed in more detail for Central Europe. The two components of the geostrophic wind and the geostrophic vorticity were used to quantify the statistics of the monthly mean circulations. The model simulations of these geostrophic flow indices were quite realistic. In winter, the models underestimated the frequency of months with a mean flow from the east. In summer the models showed a fairly wide range in the frequency of easterlies. While one model underestimated this frequency, other models simulated too high frequencies.

Observations and models showed similar relations between variations in the atmospheric circulations, and variations in temperature and precipitation. These relations were used to estimate biases in simulated circulations and biases in temperature and precipitation. We found that circulation induced biases in temperature were modest (up to $2^{\circ} \mathrm{C}$ ), and smaller than temperature biases from other sources. The simulated amplitude of the mean annual cycle in temperature and the simulated frequency distribution of monthly mean temperatures were in general realistic. The models differed significantly in their simulation of cold winter months.

The precipitation simulations showed rather high biases for some models (up to 50\% overestimation). Circulation biases appeared to have a major influence on precipitation, and range from $-30 \%$ to $+30 \%$. Precipitation distributions were fairly realistic, when scaled with the simulated mean precipitation, but all model underestimate variability in winter.

We analysed climate changes simulated by the five selected models for the A1B emission scenario. The models appeared to differ significantly with respect to the simulated circulation changes at the end of the 21 st century. One model simulated a strong increase in the strength of westerly flow in winter, while the other models simulated much weaker increases. Two models simulated pronounced pressure changes over Europe in late summer, while the other models simulated weaker or no changes. These differences in circulation changes had a profound influence on precipitation changes. In late summer, simulated precipitation change ranged from $-50 \%$ to $+20 \%$. Precipitation changes were probably affected also by differences in the simulated change in sea surface temperature over the North Atlantic. The two models that simulated strong reductions in summer precipitation, were likely to have suffered from severe soil moisture depletion, which may have contributed to a further reduction in precipitation.

Circulation changes affected simulated temperature changes as well. With respect to the mean changes the contribution of circulation changes were important, but not dominant. This implies that the simulation of the change in mean temperature was rather robust. This change was fairly close to the simulated change in global mean temperature for each model. However, the simulated change for cold winter months and warm summer months differed widely between the models. Some models simulate a major decrease in temperature variability in winter, while other models do not. In summer we saw a wide range in simulated changes in the temperature distribution. The two models with strong circulation changes, simulated a rather dramatic increase in the frequency of very warm months. This was probably due to a large contribution of summer drying to the warming of warm months in the simulations by these models.

These results imply that the predictability of the change in several important features of the European climate is limited. This holds in particular for circulation changes, for precipitation changes in late summer and for changes in the occurrence of very cold winter months and very warm summer months.

Acknowledgements. We acknowledge the international modelling groups for providing their data for analysis, the Program for Climate Model Diagnosis and Intercomparison (PCMDI) for collecting and archiving the model data, the JSC/CLIVAR Working Group on Coupled Modelling (WGCM) and their Coupled Model Intercomparison Project (CMIP) and Climate Simulation Panel for organising the model data analysis activity, and the IPCC WG1 TSU for technical support. The IPCC Data Archive at Lawrence Livermore National Laboratory is supported by the Office of Science, US Department of Energy.

We acknowledge the anonymous reviewers for their useful comments, which have led to important improvements of this paper.

Edited by: H. Wernli

\section{References}

Bader, D., Achuta Rao, K., Covey, C., Doutriaux, C., Fionino, M., Gleckler, P., Philips, T., Sperber, K., and Taylor, K.: An appraisal of coupled climate model simulations, Tech. Rep. UCRL-TR202550, University of California, Lawrence Livermore National Laboratory, 2004.

Bromwich, D. H. and Fogt, R. L.: Strong trends in the skill of the ERA-40 and NCEP-NCAR reanalysies in the high and midlatitudes of the southern hemisphere, J. Climate, 17, 4603-4619, 2004.

D’Andrea, F., Tibaldi, S., Blackburn, M., Boer, G., Dq́ué, M. Dugas, B., Ferranti, L., Hunt, B., Kitho, A., Randall, D., Roeckner, E., Rowell, D., Straus, D., Sato, N., van den Dool, H., and 
Williamson, D.: Northern hemisphere atmospheric blocking as simulated by 15 atmospheric general circulation models in the period 1979-1988, Climate Dyn., 14, 385-407, 1998.

Delworth, T. L., Broccoli, A. J., Rosati, A., Stouffer, R. J., Balaji, V., Beesley, J. A., Cooke, W. F., Dixon, K. W., Dunne, J., Dunne, K. A., Durachta, J. W., Findell, K. L., Ginoux, P., Gnanadesikan, A., Gordon, C. T., Griffies, S. M., Gudgel, R., Harrison, M. J., Held, I. M., Hemler, R. S., Horowitz, L. W., Klein, S. A., Knutson, T. R., Kushner, P. J., Langenhorst, A. R., Lee, H. C., Lin1, S. J., Lu, J., Malyshev, S. L., Milly, P. C. D., Ramaswamy, V., Russell, J., Schwarzkopf, M. D., Shevliakova, E., Sirutis, J. J., Spelman, M. J., Stern, W. F., Winton, M., Wittenberg, A. T., Wyman, B., Zeng, F., and Zhang, R.: GFDL's CM2 global coupled climate models - Part 1: Formulation and simulation characteristics, J. Climate, accepted, 2005.

Ding, Y., Xu, Y., Zhao, Z.-C., Luo, Y., and Gao, X.: Climate change scenarios over east Asia and China in the future 100 years, Climate Change Newsletter, pp. 2-4, 2004.

Furevik, T., Bentsen, M., Drange, H., Kvamsto, N., and Sorteberg, A.: Description and evaluation of the Bergen climate model: ARPEGE coupled with MICOM, Climate Dyn., 21, 2751, 2003.

Gordon, C., Cooper, C., Senior, C. A., Banks, H., Gregory, J. M., Johns, T. C., Mitchell, J. F. B., and Wood, R. A.: The simulation of SST, sea ice extents and ocean heat transport in a version of the Hadley Centre coupled model without flux adjustments, Climate Dyn., 16, 147-168, 2000.

Gordon, H. B., Rotstayn, L. D., McGregor, J. L., Dix, M. R., Kowalczyk, E. A., O'Farrell, S. P., Waterman, L. J., Hirst, A. C., Wilson, S. G., Collier, M. A., Watterson, I. G., and Elliott, T. I.: The CSIRO Mk3 climate system model, Tech. Rep. 60, CSIRO Atmospheric Research, Aspendale, 2002.

Hazeleger, W.: Can global warming affect tropical heat transport?, Geophys. Res. Lett., 32, L22 701, doi:10.1029/2005GL023450, 2006.

IPCC: Climate Change 2001: The Scientific Basis. Contribution of Working Group I to the Third Assessment Report of the Intergovernmental Panel on Climate Change (IPCC) [Houghton, J. T., Y. Ding, D. J. Griggs, M. Noguer, P. J. van der Linden, X. Dai, K. Maskell and C. A. Johnson (eds)], Cambridge University Press, Cambridge, UK and New York, NY, also available from http://www.ipcc.ch, 2001.

Johns, T., Durman, C., Banks, H., Roberts, M., McLaren, A., Ridley, J., Senior, C., Williams, K., Jones, A., Keen, A., Rickard, G., Cusack, S., Joshi, M., Ringer, M., Dong, B., Spencer, H., Hill, R., Gregory, J., Pardaens, A., Lowe, J., Bodas-Salcedo, A., Stark, S., and Searl, Y.: HadGEM1 - model description and analysis of preliminary experiments for the IPCC Fourth Assessment Report, Tech. Rep. 55, U.K. Met Office, Exeter, U.K., 2004.

Jones, P. D., Davies, T. D., Lister, D. H., Slonosky, V., Jonsson, T., Barring, L., Jonsson, P., Maheras, P., Kolyva-Machera, F., Barriendos, M., Martin-Vide, J., Rodriquez, R., Alcoforado, M. J., Wanner, H., Pfister, C., Luterbacher, J., Rickli, R., Schuepbach, E., Kaas, E., Schmith, T., Jacobeit, J., and Beck, C.: Monthly mean pressure reconstructions for europe for the 1780-1995 period, Int. J. Climatol., 19, 347-364, 1999.

Jylhä, K., Tuomenvirta, H., and Ruosteenoja, K.: Climate change projections for finland during the 21 st century, Boreal Env. Res., 9, 127-152, 2004.
K-1 model developers: K-1 coupled model (MIROC) description, Tech. Rep. 1, Center for Climate System Research, University of Tokyo, 2004.

Kim, S.-J., Flato, G. M., de Boer, G. J., and McFarlane, N. A.: A coupled climate model simulation of the last glacial maximum, part 1: transient multi-decadal response, Climate Dyn., 19, 515537, 2002.

Lenderink, G., van Ulden, A. P., van den Hurk B., and van Meijgaard, E.: Summertime inter-annual temperature variability in an ensemble of regional model simulations: analysis of the surface energy budget, Climatic Change, accepted, 2006.

Lucarini, L. and Russell, G. L.: Comparison of mean climate trends in the northern hemisphere between National Centers for Environmental Prediction and two atmosphere-ocean model forced runs, J. Geophys. Res., D15, doi:10.1029/2001JD001247, 2002.

Marti, O., Braconnot, P., Bellier, J., Benshila, R., Bony, S., Brockmann, P., Cadulle, P., Caubel, A., Denvil, S., Dufresne, J. L., Fairhead, L., Filiberti, M.-A., Fichefet, T., Friedlingstein, P., Grandpeix, J.-Y., Hourdin, F., Krinner, G., Lévy, C., Musat, I., and Talandier, C.: : The new IPSL climate system model: IPSLCM4, Tech. rep., Institut Pierre Simon Laplace des Sciences de l'Environnement Global, IPSL, Case 101, 4 place Jussieu, Paris, France, 2005.

Min, S.-K., Legutke, S., Hense, A., and Kwon, W.-T.: Internal variability in a 1000-year control simulation with the coupled climate model ECHO-G. Part I: near surface temperature, precipitation, and mean sea level pressure, Tellus, 57A, 605-621, 2005.

New, M., Hulme, M., and Jones, P. D.: Representing twentiethcentury space-time climate variability. Part 1: Development of a 1961-90 mean monthly terrestrial climatology, J. Climate, 12, 829-856, 1999.

New, M., Hulme, M., and Jones, P.: Representing twentieth-century space-time climate variability. Part II: Development of a 190196 monthly grids of terrestrial surface climate, J. Climate, 13, 2217-2238, 2000.

Pal, J. S., Giorgi, F., and Bi, X.: Consistency of recent European summer precipitation trends and extremes with future regional climate projections, Geophys. Res. Lett., 31, L13 202, doi:10.1029/2004GL019836, 2004.

Schär, C., Vidale, P. L., Lüthi, D., Frei, C., Häberli, C., Liniger, M. A., and Appenzeller, C.: The role of increasing temperature variability in european summer heatwaves, Nature, 427, 332336, 2004.

Schmidt, G. A., Ruedy, R., Hansen, J. E., Aleinov, I., Bell, N., Bauer, M., Bauer, S., Cairns, B., Canuto, V., Cheng, Y., Del Genio, A., Faluvegi, G., Friend, A. D., Hall, T. M., Hu, Y., Kelley, M., Kiang, N. Y., Koch, D., Lacis, A. A., Lerner, J., Lo, K. K., Miller, R. L., Nazarenko, L., Oinas, V., Perlwitz, J., Perlwitz, J., Rind, D., Romanou, A., Russell, G. L., Sato, M., Shindell, D. T., Stone, P. H., Sun, S., Tausnev, N., Thresher, D., and Yao, M.-S.: Present day atmospheric simulations using GISS ModelE: Comparison to in-situ, satellite and reanalysis data, J. Climate, 19, 153-192, 2006.

Schmittner, A., Latif, M., and Schneider, B.: Model projections of the North Atlantic thermohaline circulation for the 21 st century assessed by observations, Geophys. Res. Lett., 32, L23 710, doi:10.1029/2005GL024368, 2005.

Thorpe, R. P.: The impact of changes in atmospheric and land surface physics on the thermohaline circulation response to anthro- 
pogenic forcing in HadCM3 and HadCM2, Climate Dyn., 24, 449-456, 2005.

Turnpenny, J. R., Crossley, J. F., Hulme, M., and Osborne, T. J.: Air flow influences on local climate: comparison of a regional climate model with observations over the United Kingdom, Climate Res., 20, 189-202, 2002.

Uppala, S. M., Kålberg, P. W., Simmons, A. J., Andrae, U., da Costa Bechtold, V., Fiorino, M., Gibson, J. K., Haseler, J., Hernandez, A., Kelly, G. A., Li, X., Onogi, K., Saarinen, S., Sokka, N., Allan, R. P., Anderson, E., Arpe, K., Balmaseda, M. A., Beljaars, A. C. M., van den Berg, L., Bidlot, J., Borman, N., Caires, S., Dethof, A., Dragosavac, M., Fisher, M., Fuentes, M., Hagemann, S., Hólm, E., Hoskins, B. J., Isaksen, L., Janssen, P. A. E. M., Jenne, R., McNally, A. P., Mahfouf, J.-F., Mocrette, J.-J., Rayner, N. A., Saunders, R. W., Simon, P., Sterl, A., Trenberth, K. E., Untch, A., Vasiljevic, D., Viterbo, P., and Woollen, J.: The ERA-40 re-analysis, Quart. J. Roy. Meteor. Soc., 130, 2961-3012, doi:10.1256/qj.04.176, 2005.

van den Hurk, B., Hirschi, M., Lenderink, G., van Meijgaard, E., van Ulden, A. P., Rockel, B., Hagemann, S., Graham, P., Kjellström, E., and Jones, R.: Soil control on run-off response to climate change in regional climate model simulations, J. Climate, 18, 3536-3551, 2005. van Oldenborgh, G. J. and van Ulden, A.: On the relationship between global warming, local warming in the Netherlands and changes in circulation in the 20th century, Int. J. Climatol., 23, 1711-1724, doi:10.1002/joc.966, 2003.

van Ulden, A. P., Lenderink, G., van den Hurk, B., and Van Meijgaard, E.: Circulation statistics and climate change in central Europe: PRUDENCE simulations and observations, Climatic Change, accepted, 2006.

Volodin, E. M. and Diansky, N. A.: El-Niño reproduction in coupled general circulation model of atmosphere and ocean, Russian meteorology and hydrology, 12, 5-14, 2004.

Washington, W. M., Weatherly, J. W., Meehl, G. A., Semtner, Jr., A. J., Bettge, T. W., Craig, A. P., Strand, Jr., W. G., Arblaster, J., Wayland, V. B., James, R., and Zhang, Y.: Parallel climate model (PCM) control and transient simulations, Climate Dyn., 16, 755-774, 2000.

Yu, Y., Zhang, X., and Guo, Y.: Global coupled ocean- atmosphere general circulation models in LASG/IAP, Adv. Atmos. Sci., 21, 444-455, 2004.

Yukimoto, S. and Noda, A.: Improvements of the Meteorological Research Institute Global Ocean-atmosphere Coupled GCM (MRI-CGCM2) and its climate sensitivity, Tech. Rep. 10, NIES, Japan, 2002. 